\title{
GNRE
}

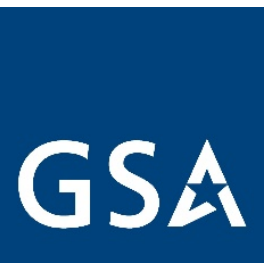

\section{Blueprint for Integrating Grid- Interactive Efficient Building (GEB) Technologies into U.S. General Services Administration Performance Contracts}

Jesse Dean, Phil Voss, Douglas Gagne, Deb Vásquez, and Rois Langner

Produced under direction of the U.S. General Services Administration by the National Renewable Energy Laboratory (NREL) under Interagency Agreement IAG-11-01815.

NREL is a national laboratory of the U.S. Department of Energy Office of Energy Efficiency \& Renewable Energy Operated by the Alliance for Sustainable Energy, LLC

This report is available at no cost from the National Renewable Energy Laboratory (NREL) at www.nrel.gov/publications.

Strategic Partnership Project Report NREL/TP-7A40-78190

May 2021

Contract No. DE-AC36-08G028308 

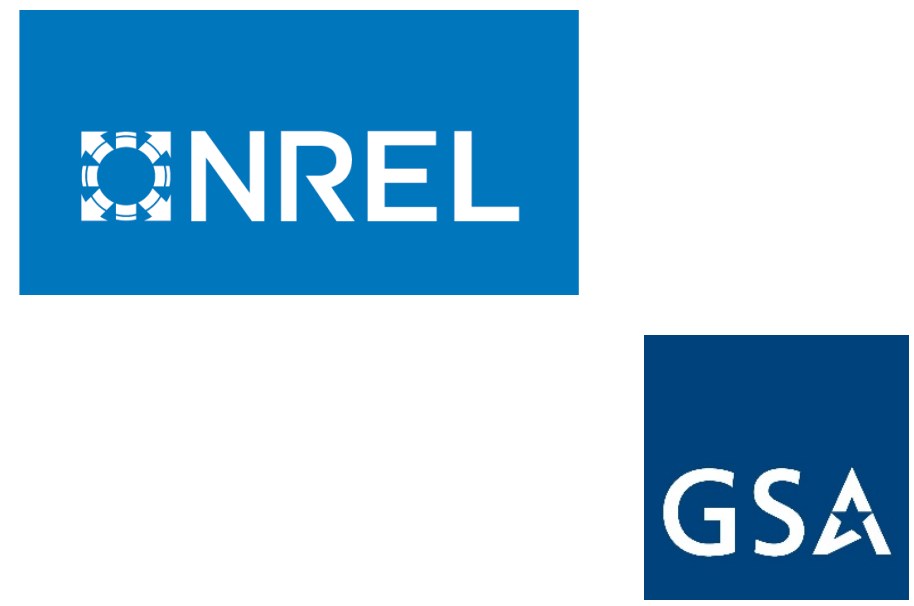

\title{
Blueprint for Integrating Grid- Interactive Efficient Building (GEB) Technologies into U.S. General Services Administration Performance Contracts
}

\author{
Jesse Dean, Phil Voss, Douglas Gagne, \\ Deb Vásquez, and Rois Langner
}

\section{Suggested Citation}

Dean, Jesse, Phil Voss, Douglas Gagne, Deb Vásquez, and Rois Langner. 2021. Blueprint for Integrating Grid-Interactive Efficient Building (GEB) Technologies into U.S. General Services Administration Performance Contracts. Golden, CO: National Renewable Energy Laboratory. NREL/TP7A40-78190. https://www.nrel.gov/docs/fy21osti/78190.pdf.

NREL is a national laboratory of the U.S. Department of Energy Office of Energy Efficiency \& Renewable Energy Operated by the Alliance for Sustainable Energy, LLC

This report is available at no cost from the National Renewable Energy Laboratory (NREL) at www.nrel.gov/publications.

National Renewable Energy Laboratory 15013 Denver West Parkway Golden, CO 80401

303-275-3000 • www.nrel.gov
Strategic Partnership Project Report NREL/TP-7A40-78190

May 2021

Contract No. DE-AC36-08GO28308 


\section{NOTICE}

This work was authored by the National Renewable Energy Laboratory, operated by Alliance for Sustainable Energy, LLC, for the U.S. Department of Energy (DOE) under Contract No. DE-AC36-08GO28308. Support for the work was also provided by the U.S. General Services Administration under Contract No. IAG-11-01815. The views expressed in the article do not necessarily represent the views of the DOE or the U.S. Government. The U.S. Government retains and the publisher, by accepting the article for publication, acknowledges that the U.S. Government retains a nonexclusive, paid-up, irrevocable, worldwide license to publish or reproduce the published form of this work, or allow others to do so, for U.S. Government purposes.

This report is available at no cost from the National Renewable Energy Laboratory (NREL) at www.nrel.gov/publications.

U.S. Department of Energy (DOE) reports produced after 1991 and a growing number of pre-1991 documents are available free via www.OSTI.gov.

NREL prints on paper that contains recycled content. 


\section{Acknowledgments}

This report was developed for and sponsored by the U.S. General Services Administration (GSA). Kinga Porst Hydras and Ken Sandler with GSA's Office of Federal High-Performance Green Buildings served as project managers and lead reviewers. The report was authored by Jesse Dean, Phil Voss, Douglas Gagne, Deb Vásquez, and Rois Langner of the National Renewable Energy Laboratory (NREL). Valuable guidance and reviews were also provided by Tom Harris and Michael Callahan of NREL.

GSA staff Sharon Conger, Cullen Rabel, Erin Lannon, Kevin Powell, Mike Virgilio, Nathan Ingersoll, Joshua Banis, and Tyler Harris provided valuable reviews and feedback.

The authors also thank Monica Neukomm of the U.S. Department of Energy Building Technologies Office; Jay Wrobel, Schuyler Schell, and Hayes Jones of the Federal Energy Management Program; and Rebecca Esau and Cara Carmichael from RMI for their reviews and input. 


\section{List of Acronyms}
AHU air handling unit
AMI advanced metering infrastructure
ATO authority to operate
BAS building automation system
CAISO California Independent System Operator
CHP combined heat and power
DER distributed energy resource
DOE Department of Energy
ECM energy conservation measure
EMIS energy management information systems
ESPC energy savings performance contract
EV electric vehicle
FEMP Federal Energy Management Program
GEB grid-interactive efficient buildings
GPG GSA's Proving Ground
GSA General Services Administration
ESCO energy services company
ESPC energy savings performance contract
HVAC heating, ventilation, and air conditioning
IDIQ indefinite delivery indefinite quantity
IGA investment-grade audit
IoT Internet of Things
IPMPV International Performance Measurement and Verification Protocol
LED light-emitting diode
$\mathrm{M} \& \mathrm{~V} \quad$ measurement and verification
NDER National Deep Energy Retrofit Program
NIST National Institute of Standards and Technology
NREL National Renewable Energy Laboratory
NOO Notice of Opportunity
O\&M operations and maintenance
PA preliminary assessment 


$\begin{array}{ll}\text { PBS } & \text { Public Buildings Service } \\ \text { PV } & \text { photovoltaic } \\ \text { RRPM } & \text { Risk, Responsibility, and Performance Matrix } \\ \text { RTU } & \text { rooftop unit } \\ \text { T\&D } & \text { transmission and distribution } \\ \text { TOU } & \text { time-of-use } \\ \text { UESC } & \text { utility energy service contract } \\ \text { U.S.C. } & \text { U.S. Code } \\ \text { VAR } & \text { volt-ampere reactive } \\ \text { VFD } & \text { variable frequency drive }\end{array}$




\section{Executive Summary}

Grid-interactive efficient buildings (GEBs) offer an integrated approach to coordinating building energy loads for cost savings, continuous demand management, and to optimize energy use for additional grid services. Advanced controls enable flexibility regarding when and how building electrical and thermal loads are operated. In an optimized manner, GEBs can mitigate peak demand challenges, enhance grid reliability/energy resiliency, and balance the supply of renewable energy generation.

As the manager of the largest portfolio of commercial office space in the United States, the U.S. General Services Administration (GSA) is in the process of identifying its facilities with the highest potential for cost-effective GEB projects to gain the many the benefits offered by GEB. GSA has historically demonstrated leadership in implementing deep energy retrofits through its National Deep Energy Retrofit (NDER) program. Over the three rounds of the NDER program, GSA has set aggressive goals, collaborated with a diverse set of stakeholders, and used an iterative and holistic design process to retrofit facilities for an average 33\% whole-building energy savings compared to average federal energy savings performance contract (ESPC) savings of $18 \%$.

Now, with this GEB blueprint, GSA seeks to expand its innovative deployment of the NDER program by incorporating demand flexibility and grid integration strategies that bring additional energy and cost savings along with increased resilience and greenhouse gas reductions. Even in circumstances where a site may not currently be suitable for a full GEB retrofit, there may still be value in taking steps toward making the facilities GEB ready for future GEB integration.

Some keys to a successful GEB project are:

- Strategic selection of sites with utility rates and incentives favorable to GEB;

- Identification of GEB measures as a priority early in the project development process;

- Stakeholder engagement to ensure understanding and to maximize GEB impact;

- Integration of GEB measures within major building renovations; and

- Careful consideration of GEB measurement and verification methodologies.

This blueprint outlines a screening process that will enable GSA to narrow down sites across its large portfolio of buildings to a prioritized list of candidate sites with the greatest potential for cost-effective GEB implementation. The first phase, market screening, rules out sites with low electric utility costs and minimal incentives, as they are unlikely to be cost effective. The second phase considers the sites' utility rate details to identify potential opportunities, and the third phase relies upon detailed interval data to rank the most promising GEB opportunities. Each phase of screening can be informed by a distributed energy resource screening process.

This report then outlines challenges - and solutions - related to contracting for demand flexibility cost savings, impacts on building tenants, GSA and site staff training for use of the GEB measures, and varying technology maturities of GEB measures. It describes best practices and recommendations for GEB implementation for the five phases of performance contract development and implementation. These phases are shown in Figure ES-1. 


\section{Phase 1 - Acquisition Planning}

\section{Phase 3 - Utility/Energy Services Company Selection and Preliminary Assessment}

\section{Phase 3 - Pre-Award Project Development}

\section{Phase 4 - Project Implementation}

\section{Phase 5 - Post-Acceptance Performance}

\section{Figure ES-1. Performance contracting phases}

Image Credit: Federal Energy Management Program

Additional recommendations related to GEB analysis and inclusion in the notice of opportunity, preliminary assessment, and investment grade audit are included, as well as GEB measure evaluation metrics and measurement and verification recommendations.

This proposed blueprint can help guide GSA staff in augmenting deep energy retrofits to include GEB strategies and onsite renewable energy systems that drive further energy cost savings, carbon emissions reductions, and regional benefits to the local utility. 


\section{Table of Contents}

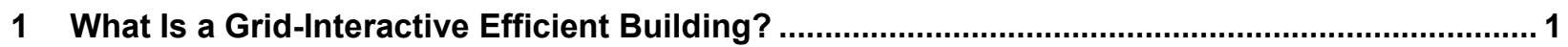

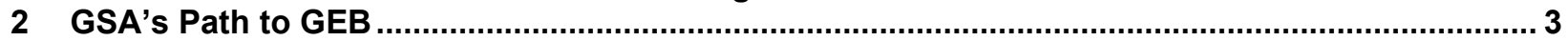

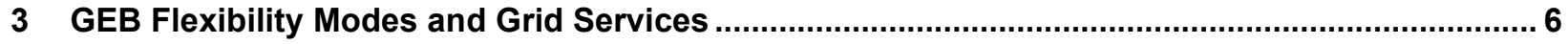

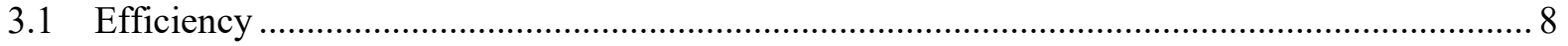

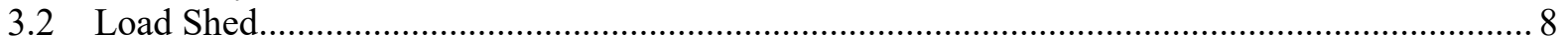

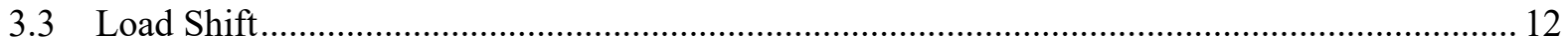

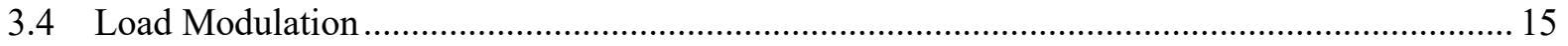

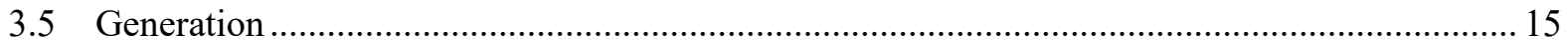

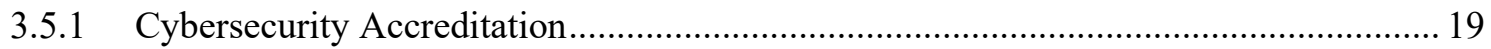

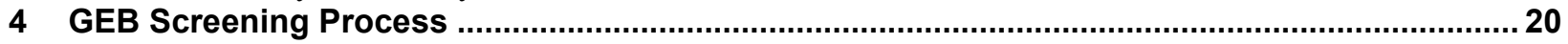

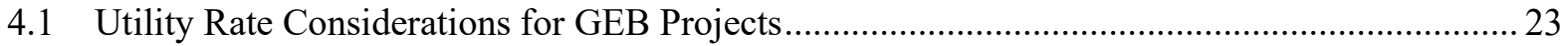

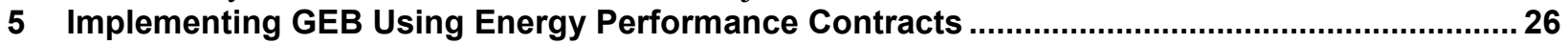

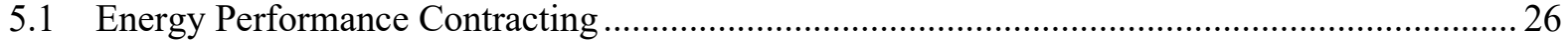

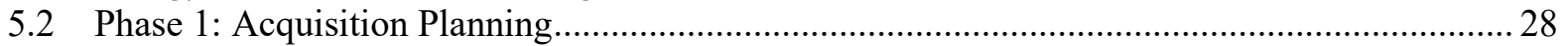

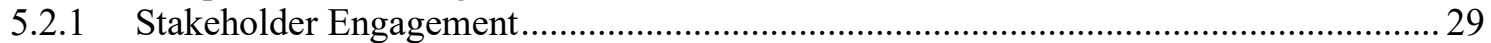

5.3 Phase 2: Contractor Selection and Preliminary Assessment …............................................... 30

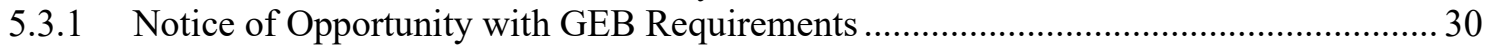

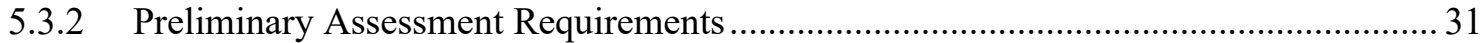

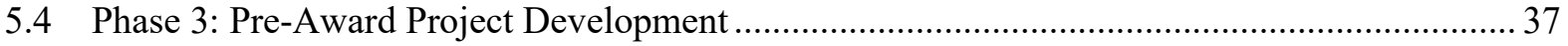

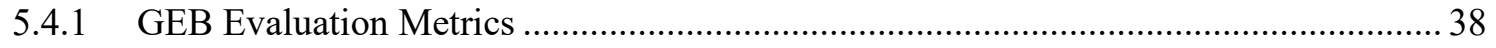

5.4.2 IGA M\&V, Performance Assurance, and Risk Allocation .......................................... 41

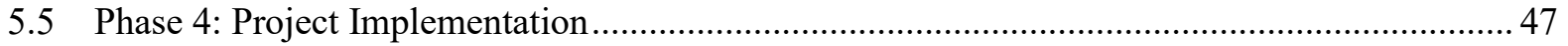

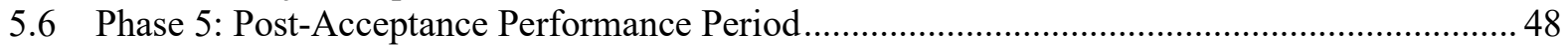

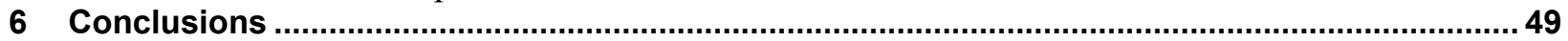

Appendix A. Utility Rate Structure and Grid Services Analysis ............................................50

Appendix B. GEB ECM Write Up Considerations..............................................................52

Appendix C. Preliminary Assessment Documentation ....................................................... 53

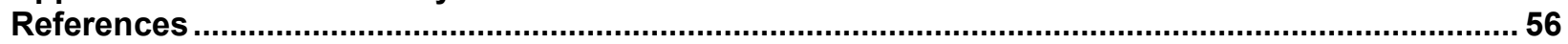




\section{List of Figures}

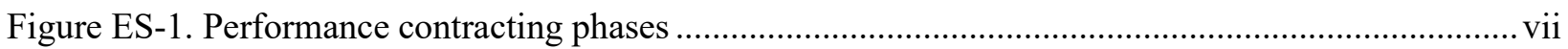

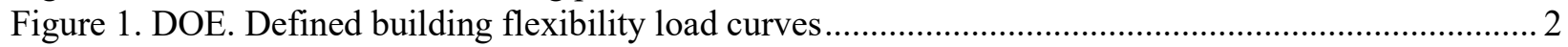

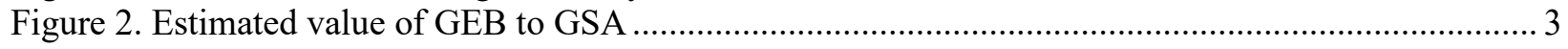

Figure 3. GSA NDER program percent energy savings per building, 2012-2018 ................................. 5

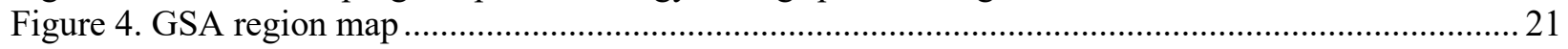

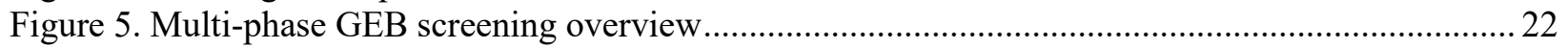

Figure 6. National demand charge rates and GSA site locations ................................................... 24

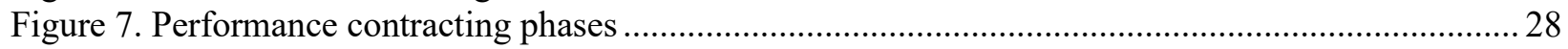

Figure 8. Example inverted electrical load profile ............................................................................ 33

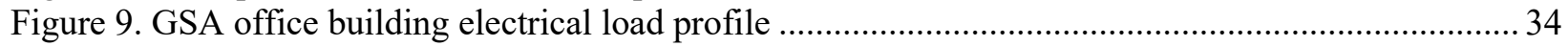

Figure 10. Generic commercial building hourly end-use load profile ................................................. 39

Figure 11. Performance contracts annual energy cost savings variability ............................................. 45

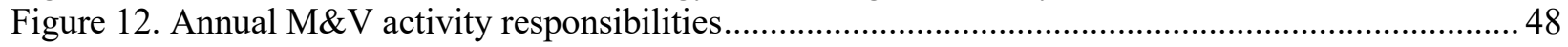

Figure A-1. Electric costs and estimated demand charges at GSA sites (GSA GIS Platform).................. 50

\section{List of Tables}

Table 1. Grid Interactive Buildings Grid Services............................................................................... 7

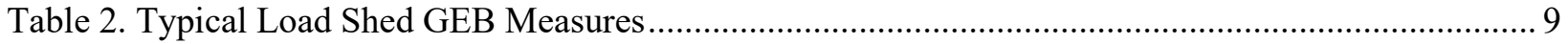

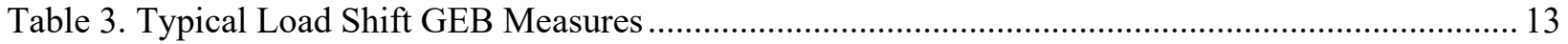

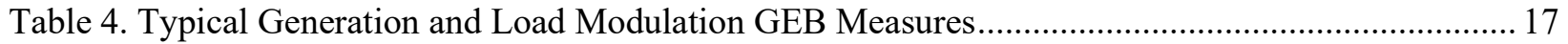

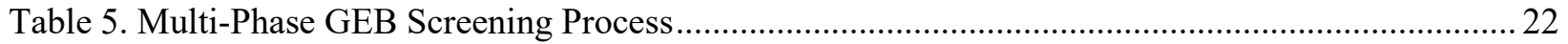

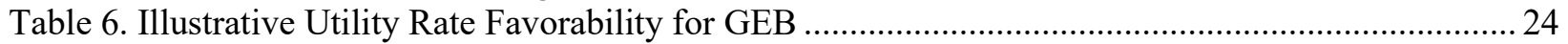

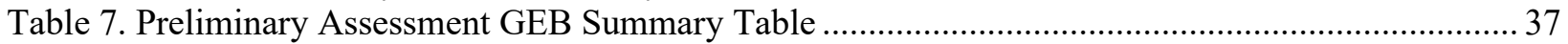

Table 8. Investment Grade Audit GEB Metrics Summary …................................................................ 40

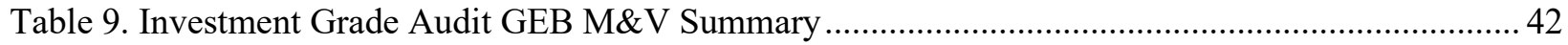




\section{What Is a Grid-Interactive Efficient Building?}

The General Services Administration (GSA), in its role designing, building, operating, and managing federal buildings, has been a leader in energy efficiency for several decades. GSA is now exploring additional opportunities for demand flexibility, cost savings, and innovation in the emerging field of grid-interactive efficient buildings (GEBs).

The U.S. Department of Energy (DOE) Building Technologies Office defines a GEB as "an energy efficient building with smart technologies characterized by the active use of distributed energy resources (DERs) to optimize energy use for grid services, occupant needs and preferences, and cost reductions in a continuous and integrated way. ${ }^{1}$

In this chapter:

- Defining GEBs

- The case for GEBs

- GEB strategies

In other words, GEB builds on the well-established discipline of energy efficiency by adding strategies and technologies to also manage peak demand and coordinate buildings' electrical loads, taking into account peak usage hours, renewable generation, storage options, and resiliency needs as appropriate.

Combining and balancing a diverse set of needs from both the building owner and local utility perspective requires building operations to be more controllable, flexible, and integrated. Many electrical loads in buildings can be operated in a more flexible manner, and through advanced controls, can be managed to operate at specific times and at different output levels. The ability to deploy more advanced continuous demand management strategies at the building level can help address peak demand challenges, which are becoming increasingly important to utilities.

Studies have shown that $10 \%-20 \%$ of commercial building peak load can be temporarily managed or curtailed to provide grid services with the use of state-of-the-art sensors and controls. ${ }^{2,3}$ In addition, it is estimated that using state-of-the-art sensors and controls across the commercial building stock could lead to annual energy savings of $29 \%$ through use of highperformance sequences of operations and optimizing programmable settings based on occupancy patterns, as well as detecting and diagnosing equipment operation and installation problems. ${ }^{4}$

Building operators can gain significant financial benefit from applying GEB technologies and their associated demand flexibility strategies. High demand charges, demand response programs, time-of-use (TOU) rates (or other dynamic pricing schemes), utility rebates and incentives, as well as energy efficiency by itself can all create potentially lucrative opportunities to transform federal buildings into GEBs.

DOE has identified four categories of GEB strategies, as illustrated in Figure $1^{1}$ :

1. Energy efficiency

2. Load shed

3. Load shift

4. Modulation. 


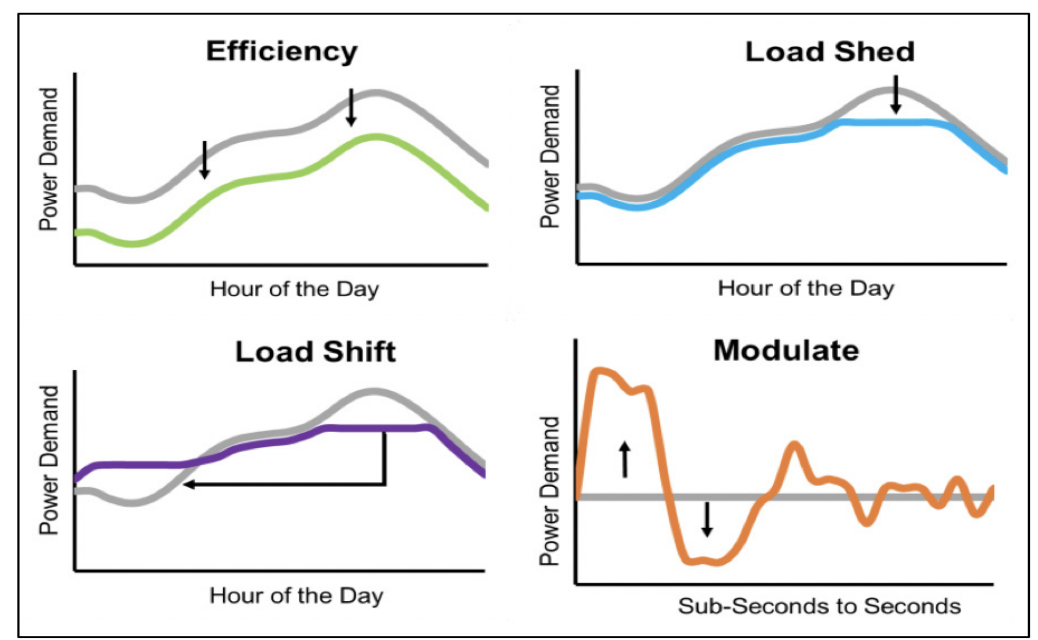

Figure 1. DOE. Defined building flexibility load curves

(Image Credit: DOE GEB Overview)

DOE defines these categories as follows:

1. Energy efficiency: the ongoing reduction in energy use while providing the same or improved level of building function.

2. Load shed: the ability to reduce electricity use for a short time period and typically on short notice. Shedding is typically dispatched during peak demand periods and during emergencies.

3. Load shift: the ability to change the timing of electricity use. In some situations, a shift may lead to changing the amount of electricity that is consumed. Load shift in the GEB Technical Report Series focuses on intentional, planned shifting for reasons such as minimizing demand during peak periods, taking advantage of lower electricity prices, or reducing the need for renewable electricity generation curtailment. For some technologies, there are times when load shed can lead to some level of load shifting.

4. Modulation: the ability to modulate the electrical load at the subseconds-to-seconds level. This enables the capability to provide small-scale, distributed grid stability and balancing services by automatically increasing or decreasing a building's power or reactive power production. $^{5}$

Refer to Section 3 of this report for additional detail on these four GEB strategies. Federal facilities present many opportunities for greater efficiency, load shedding, and load shifting. In the context of federal buildings, load modulation activities that are directly implemented via a grid signal from the utility can be a challenging strategy to implement if they require ceding direct control of some building equipment to an external entity such as a utility, which can create cybersecurity challenges. 


\section{GSA's Path to GEB}

GSA is exploring opportunities for building-to-grid integration at facilities where such strategies make sense to pursue. GSA's Green Building Advisory Committee, ${ }^{6}$ a panel of outside experts that advises the government on practices and technologies to make the federal building stock more sustainable, developed two sets of findings and recommendations in 2019 recommending the federal adoption of GEB strategies.

The Committee's first Advice Letter and Report:

In this chapter:

- GSA analysis, recommendations, and policy related to GEB

- National Deep Energy Retrofit program history and future goals

Recommendations for Adoption of Grid-Integrated Building Policy Provisions ${ }^{7}$ presented initial findings and recommendations on why the federal government should launch building-to-grid integration policies and practices. Its second Advice Letter: Federal Building \& Grid Integration: Proposed Roadmap ${ }^{8}$ provided more detailed and targeted recommendations for how the federal government should make this transition.

The Committee's highest-priority recommendations were for GSA to:

- Set federal building and grid integration policies

- Conduct grid and rate analyses

- Develop design guidance for new and existing federal buildings

- Incorporate demand savings into energy savings performance contracts (ESPCs) and utility energy service contracts (UESCs)

- Develop GEB pilot projects.

After the committee issued these recommendations, GSA sponsored RMI in 2019 to produce a feasibility study of GEB implementation at six GSA locations. ${ }^{9}$ RMI identified significant potential value streams, as illustrated in Figure 2.

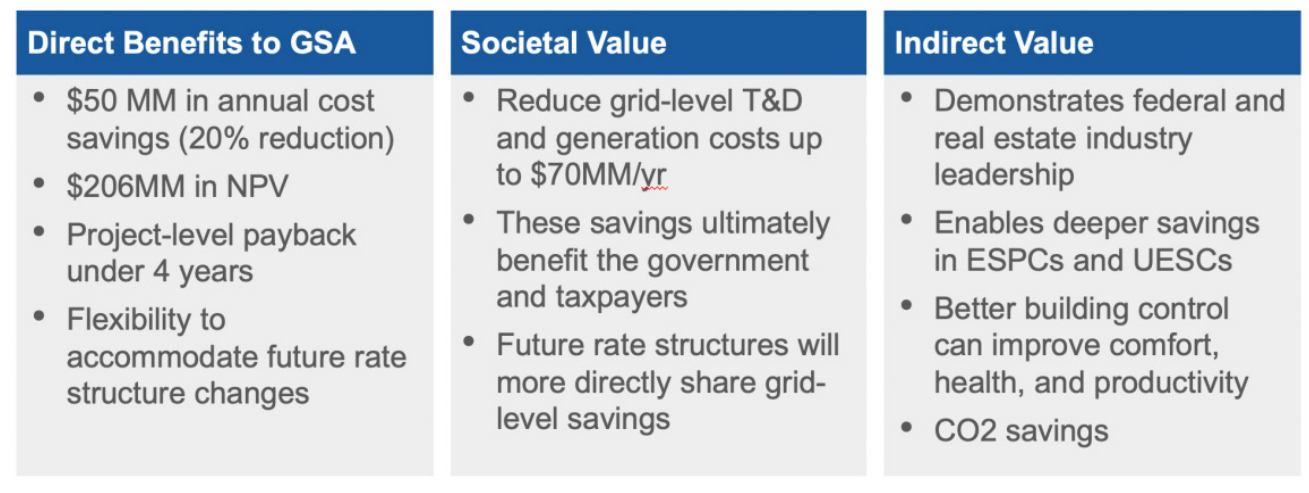

Figure 2. Estimated value of GEB to GSA

Image credit: GSA and RMI, Value Potential for Grid-Interactive Efficient Buildings in the GSA Portfolio: A CostBenefit Analysis, 2019 
In its market analysis, RMI described the primary benefits it estimated for GSA ${ }^{\mathrm{i}}$ :

- Substantial energy impacts: These measures can generate $165 \mathrm{MW}$ of peak load reduction and $180 \mathrm{GWh}$ per year in energy savings across the GSA-owned office portfolio.

- Cost-effective building-level economics: Each modeled location shows payback periods of less than four years, saving on average 30\% of annual energy costs (depending on location-specific factors).

- Sizable savings at scale: The GSA could generate $\$ 50$ million in annual cost savings, about $20 \%$ of the GSA's annual energy spend, by pursuing GEB measures for all of its owned office buildings. This would require a \$184 million up-front investment that would in turn deliver \$206 million in net present value over eight years.

- GEB measures have a short payback and a high net present value: GEB measures should be implemented now to capture value. Quick paybacks reduce the risk of uncertainty around future utility pricing, including demand charges. ${ }^{9}$ This also makes them valuable for bundling with longer-payback measures in ESPC and UESC projects to improve overall project payback.

The next step for GSA after receiving the Committee recommendations and analyzing the feasibility of employing key GEB strategies was to pilot test them at GSA facilities. Therefore, GSA's Proving Ground program (GPG), in partnership with the DOE Commercial Buildings Integration program, released a request for information in 2019 seeking technology providers to partner on GEB demonstration projects. ${ }^{10}$ In 2020, these two programs selected four GEB technology solutions to be validated in both private-sector and GSA facilities. ${ }^{11}$

At the same time, GSA's Office of Federal High-Performance Buildings engaged the National Renewable Energy Laboratory (NREL) and RMI to work with the Greater Southwest Region (Region 7) of the GSA Public Buildings Service (PBS) to explore how GEB technologies and strategies could be incorporated into multi-building UESCs then underway. This report outlines a strategy for GSA to apply portfolio wide screening and GEB best practices, particularly using UESCs and other performance contracts, as a vehicle for implementation.

Such an approach builds on GSA success in delivering deep energy savings through ESPCs since the launch of the agency's National Deep Energy Retrofit (NDER) program in 2011. Deep energy retrofits use a whole-building analysis and construction process that achieves much larger energy cost savings than those of simpler retrofits while simultaneously striving to enhance the building's value. The objectives of GSA's NDER program include:

1. Achievement of greater than $40 \%$ energy savings

2. Use of an integrative design process

\footnotetext{
${ }^{i}$ The RMI analysis was conducted using the DOE Commercial Prototype Building Models and was not based on specific GSA buildings. The energy savings and economics need to be evaluated on a case by case basis for each building, as the economics and savings can change substantially from one location to another.
} 
3. An approach informed by a whole-systems perspective

4. Improved project economics

5. Positive impacts on site and grid

6. Use of innovative technologies

7. Use of onsite renewable energy technologies. ${ }^{12}$

The GSA NDER program has become a leader in the deployment of deep energy retrofit best practices by setting aggressive goals, collaborating with a diverse set of stakeholders, and using an iterative and holistic design process to retrofit GSA facilities. Over the three rounds of the GSA NDER program, GSA achieved an average 33\% whole-building energy savings relative to average federal ESPC savings of 18\%. 3 shows the results of rounds 1-3 of GSA's NDER program.

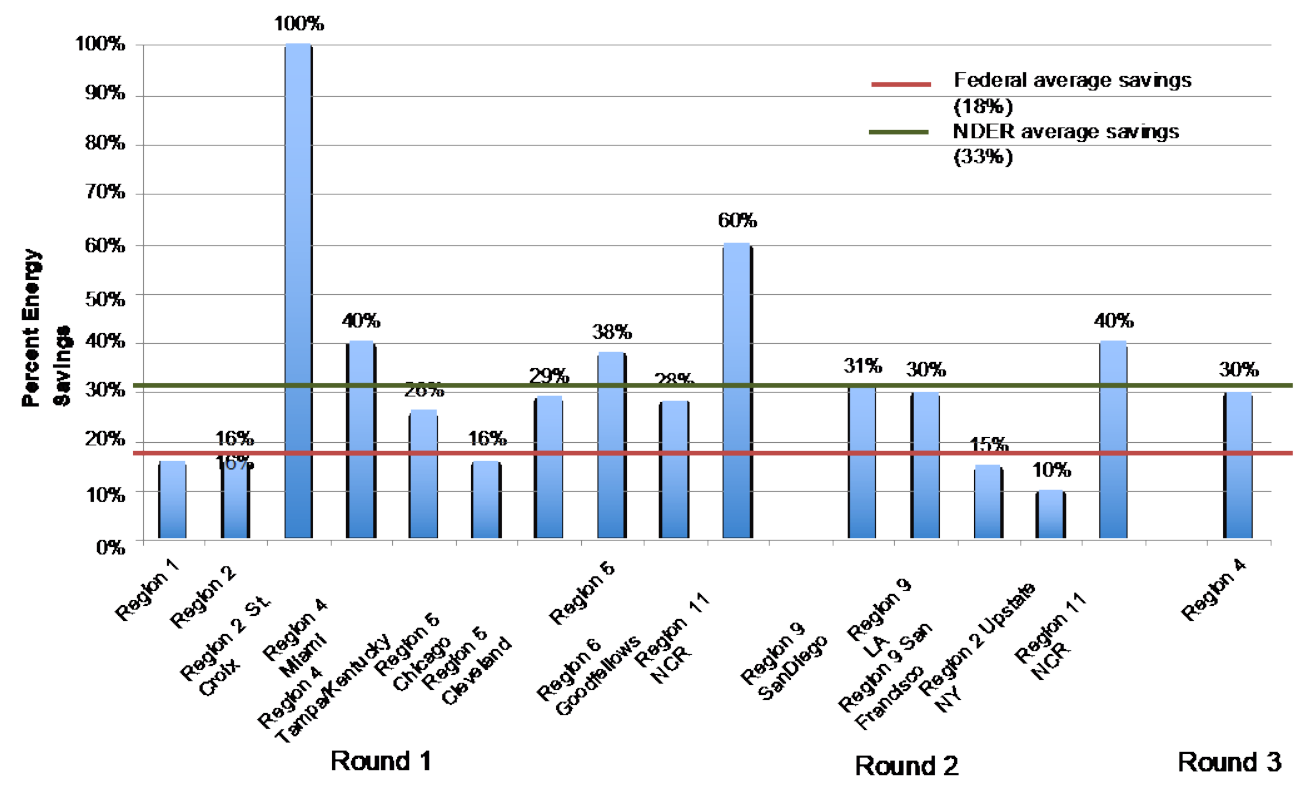

Figure 3. GSA NDER program percent energy savings per building, 2012-2018

(Image Credit: Kinga Porst Hydras, GSA)

GSA's work to integrate GEB technologies into future deep energy retrofits will drive additional energy savings/demand reductions, help meet net zero energy goals, further reduce GSA's carbon footprint, increase energy resiliency, and help address GSA's overarching sustainability goals.

The global COVID-19 pandemic dramatically impacted GSA building operations in 2020 and 2021. Many GSA staff were required to telework, leaving occupancy rates at many buildings very low. GSA also implemented ASHRAE Epidemic Task Force heating, ventilation, and airconditioning (HVAC) guidelines, which include increasing run time of HVAC equipment, disabling demand-controlled ventilation, and increasing outside air rates. As GSA develops a return-to-work plan, the incorporation of GEB and state-of-the-art smart building technologies will allow for more intelligent control of building loads, making GSA facilities more adaptable and resilient in the future. 
With this blueprint, GSA seeks to expand its innovative use of performance contracts for deep energy savings in a new direction, incorporating grid integration strategies that bring additional energy and cost savings along with resilience and renewable energy generation benefits for federal buildings and the electric grid. The next section introduces the major GEB flexibility modes in more detail, including their applications, requirements, and potential technologies.

\section{GEB Flexibility Modes and Grid Services}

Understanding the relationship between the various forms of GEB demand flexibility and grid services that are potentially incentivized by serving utilities is an important step of the evaluation process. Table 1 maps out demand flexibility modes in reference to both grid services and key characteristics of each flexibility mode. ${ }^{13}$

The flexibility modes and key characteristics are helpful for understanding how these measures would be implemented within an energy project, and particularly a performance

In this chapter:

- GEB demand flexibility modes

- Grid services including efficiency, load shed, load shift, modulation, and generation

contract. Following Table 1, each flexibility mode is discussed, with a brief explanation of its key characteristics and potential grid services. 
Table 1. Grid Interactive Buildings Grid Services ${ }^{14}$

\begin{tabular}{|c|c|c|c|c|}
\hline $\begin{array}{l}\text { Flexibility } \\
\text { Mode }\end{array}$ & \multicolumn{2}{|l|}{ Grid Services } & \multicolumn{2}{|c|}{ Key Characteristics } \\
\hline Efficiency & $\begin{array}{l}\text { Generation: Energy \& Capacity } \\
\text { Transmission \& Distribution } \\
\text { (T\&D): Non-Wires Solutions }\end{array}$ & $\begin{array}{l}\text { Persistent reduction } \\
\text { in load. Not } \\
\text { dispatchable. }\end{array}$ & $\begin{array}{l}\text { Load change: } \\
\text { Duration: } \\
\text { Response time: } \\
\text { Annual events: }\end{array}$ & $\begin{array}{l}\text { Long-term reduction } \\
\text { Equipment lifetime } \\
\text { N/A } \\
\text { Continuous }\end{array}$ \\
\hline \multirow{2}{*}{ Shed } & Contingency Reserves & $\begin{array}{l}\text { Short-term load } \\
\text { reduction to make up } \\
\text { for a shortfall in } \\
\text { generation. }\end{array}$ & $\begin{array}{l}\text { Load change: } \\
\text { Duration: } \\
\text { Response time: } \\
\text { Annual events: }\end{array}$ & $\begin{array}{l}\text { Short-term decrease } \\
\text { Up to } 1 \mathrm{hr} \\
<15 \mathrm{~min} \\
<20\end{array}$ \\
\hline & $\begin{array}{l}\text { Generation: Energy \& Capacity } \\
\text { T\&D: Non-Wires Solutions }\end{array}$ & $\begin{array}{l}\text { Load reduction during } \\
\text { peak load periods. }\end{array}$ & $\begin{array}{l}\text { Load change: } \\
\text { Duration: } \\
\text { Response time: } \\
\text { Annual events: }\end{array}$ & $\begin{array}{l}\text { Short-term decrease } \\
30 \mathrm{~min} \text { to } 4 \mathrm{hr} \\
30 \mathrm{~min} \text { to } 2 \mathrm{hr} \\
<100 \mathrm{hr} \text {, seasonal }\end{array}$ \\
\hline \multirow[b]{2}{*}{ Shift } & $\begin{array}{l}\text { Generation: Energy \& Capacity } \\
\text { T\&D: Non-Wires Solutions }\end{array}$ & $\begin{array}{l}\text { Load shifting away } \\
\text { from peak use } \\
\text { periods. }\end{array}$ & $\begin{array}{l}\text { Load change: } \\
\text { Duration: } \\
\text { Response time: } \\
\text { Annual events: }\end{array}$ & $\begin{array}{l}\text { Short-term shift } \\
30 \mathrm{~min} \text { to } 4 \mathrm{hr} \\
<1 \mathrm{hr} \\
<100 \mathrm{hr} \text {, seasonal }\end{array}$ \\
\hline & $\begin{array}{l}\text { Renewable Curtailment } \\
\text { Avoidance }\end{array}$ & $\begin{array}{l}\text { Load shifting to } \\
\text { periods of excess } \\
\text { renewable } \\
\text { generation. Not } \\
\text { dispatchable. }\end{array}$ & $\begin{array}{l}\text { Load change: } \\
\text { Duration: } \\
\text { Response time: } \\
\text { Annual events: }\end{array}$ & $\begin{array}{l}\text { Short-term shift } \\
2 \text { to } 4 \mathrm{hr} \\
\text { N/A } \\
\text { Daily }\end{array}$ \\
\hline \multirow{3}{*}{ Modulate } & Frequency Regulation & \multirow{2}{*}{$\begin{array}{l}\text { Rapid load increase } \\
\text { or reduction following } \\
\text { a grid signal. }\end{array}$} & $\begin{array}{l}\text { Load change: } \\
\text { Duration: } \\
\text { Response time: } \\
\text { Annual events: }\end{array}$ & $\begin{array}{l}\text { Rapid increase/decrease } \\
\text { Seconds to minutes } \\
<1 \text { minute } \\
\text { Continuous }\end{array}$ \\
\hline & Voltage Support & & $\begin{array}{l}\text { Load change: } \\
\text { Duration: } \\
\text { Response time: } \\
\text { Annual events: }\end{array}$ & $\begin{array}{l}\text { Rapid increase/decrease } \\
\text { Subseconds to seconds } \\
\text { Subseconds to seconds } \\
\text { Continuous }\end{array}$ \\
\hline & Ramping & $\begin{array}{l}\text { Rapid load } \\
\text { reduction/increase to } \\
\text { offset short-term } \\
\text { renewable generation } \\
\text { changes. }\end{array}$ & $\begin{array}{l}\text { Load change: } \\
\text { Duration: } \\
\text { Response time: } \\
\text { Annual events: }\end{array}$ & $\begin{array}{l}\text { Short-term decrease } \\
\text { Seconds to minutes } \\
\text { Seconds to minutes } \\
\text { Continuous }\end{array}$ \\
\hline \multirow{2}{*}{ Generate } & Ramping & $\begin{array}{l}\text { Feed on-site } \\
\text { generated or stored } \\
\text { electricity to the grid. }\end{array}$ & $\begin{array}{l}\text { Load change: } \\
\text { Duration: } \\
\text { Response time: } \\
\text { Annual events: }\end{array}$ & $\begin{array}{l}\text { Seconds to minutes } \\
\text { Short-term negative load } \\
\text { Seconds to minutes } \\
\text { Daily }\end{array}$ \\
\hline & $\begin{array}{l}\text { Generation: Energy \& Capacity } \\
\text { T\&D: Non-Wires Solutions }\end{array}$ & $\begin{array}{l}\text { Feed excess on-site } \\
\text { generated electricity } \\
\text { to the grid. }\end{array}$ & $\begin{array}{l}\text { Load change: } \\
\text { Duration: } \\
\text { Response time: } \\
\text { Annual events: }\end{array}$ & $\begin{array}{l}\text { Negative load } \\
\text { Entire generation period } \\
<1 \mathrm{hr} \\
\text { Continuous }\end{array}$ \\
\hline
\end{tabular}




\subsection{Efficiency}

Energy efficiency upgrades represent the lion's share of measures typically implemented within a performance contract. More traditional energy efficiency measures, in addition to their energy savings potential, can also have a secondary impact of lowering the building's peak electrical demand for energy conservation measures (ECMs) that have a power consumption profile that is coincident with the building electrical load profile. For example, if double-pane windows, roof insulation, lower-wattage light-emitting diode (LED) lighting, more efficient chillers, and so forth are implemented, these measures all collectively contribute to modifying the building load profile and lowering peak electrical demand. At their core, GEB technologies represent an opportunity to combine demand flexibility with standard energy efficiency measures. When GEB measures are considered, they should be evaluated in reference to the reduced demand that will result from the core energy efficiency measures that are being implemented in the project and any standard efficiency measure that has coincident peak power implications should be evaluated for additional GEB control functionality, such as LED lighting plus lighting control.

\subsection{Load Shed}

Load shed measures typically involve implementing supervisory control sequences to curtail electrical loads. Load shed activities are typically implemented over shorter durations of 15 minutes to 4 hours, with required response time typically between 15 minutes and 2 hours. They normally occur fewer than 20 times per year (or cumulatively for less than 100 hours per year). Load can also be reduced using generation or storage, and specifics of this are discussed in Section 3.5 Load Generation.

Given that there is a lot of variability among demand response programs across the United States, understanding how each specific program works - the load that needs to be shed per building, the number of demand response events per year, the number of years the incentive will be available, and the way the utility account will be credited - is important to understand at the beginning of the project. These demand response programs are typically ongoing programs that require the site to be able to meet the demand response requirements when the utility system requires. These measures can impact interior space conditions such as temperature, relative humidity, and interior light levels. While these considerations will be important for life-cycle cost analysis of any energy project, these types of measures may potentially add uncertainty into a performance contract's annual energy savings. All of these potential impacts need to be understood and a plan for addressing them should be created early in the performance contract project development process.

Table 2 through Table 4 outline GEB measures that are likely to be applicable to the GSA portfolio and could be implemented via a performance contract. To further illuminate GEB measures whose primary function is load shed, Table 2 subcategorizes load shed measures into building envelope, plug load, data center, domestic hot water, lighting, HVAC, and wholebuilding measures. In Table 2 the primary demand flexibility mode supported by the technologies is noted with a red $\mathrm{X}$, and supplemental flexibility modes supported are shown with a black X. 
Table 2. Typical Load Shed GEB Measures

\begin{tabular}{|c|c|c|c|c|c|c|c|c|}
\hline $\begin{array}{l}\text { Load } \\
\text { Flexibility } \\
\text { Category }\end{array}$ & \multicolumn{2}{|l|}{$\begin{array}{c}\text { Example GEB } \\
\text { Measures }\end{array}$} & $\begin{array}{l}\text { Load } \\
\text { Shed }\end{array}$ & $\begin{array}{l}\text { Load } \\
\text { Shift }\end{array}$ & $\begin{array}{l}\text { Demand } \\
\text { Response }\end{array}$ & Generation & Modulation & Efficiency \\
\hline \multirow{6}{*}{ 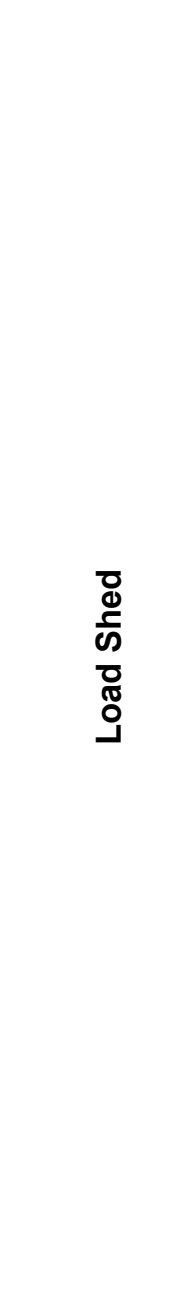 } & $\begin{array}{l}\text { Building } \\
\text { Envelope - } \\
\text { Electrochromic } \\
\text { Windows }\end{array}$ & $\begin{array}{l}\text { Electrochromic windows can be } \\
\text { controlled to reduce interior } \\
\text { cooling loads during peak periods, } \\
\text { with the window tint level adjusted } \\
\text { based on peak demand. }\end{array}$ & $\mathbf{X}$ & & $X$ & & & $X$ \\
\hline & $\begin{array}{l}\text { Building } \\
\text { Envelope - } \\
\text { Automated } \\
\text { Window } \\
\text { Shades }\end{array}$ & $\begin{array}{l}\text { Automated window shades can be } \\
\text { closed during peak cooling } \\
\text { periods to reduce demand. }\end{array}$ & $x$ & & $X$ & & & $X$ \\
\hline & $\begin{array}{l}\text { Plug Loads - } \\
\text { Advanced } \\
\text { Controls }\end{array}$ & $\begin{array}{l}\text { Advanced plug load controls can } \\
\text { be used to cycle off nonessential } \\
\text { plug loads during peak periods, or } \\
\text { to stage or shift the charging time } \\
\text { of certain devices with batteries. }\end{array}$ & $x$ & $X$ & $x$ & & & $X$ \\
\hline & $\begin{array}{l}\text { Plug Loads - } \\
\text { Connected } \\
\text { Appliances }\end{array}$ & $\begin{array}{l}\text { Appliances with Internet of Things } \\
\text { (loT) connectivity (such as WiFi or } \\
\text { Zigbee communication) can be } \\
\text { cycled off during peak periods or } \\
\text { controlled to operate during off- } \\
\text { peak periods. }\end{array}$ & $x$ & $x$ & $x$ & & & $x$ \\
\hline & $\begin{array}{l}\text { Lighting - } \\
\text { Zone } \\
\text { Switching }\end{array}$ & $\begin{array}{l}\text { Automated lighting controls can } \\
\text { be used to turn off lighting in } \\
\text { noncritical zones, with natural } \\
\text { daylighting for short periods of } \\
\text { time during peak periods. }\end{array}$ & $x$ & & & & & $x$ \\
\hline & $\begin{array}{l}\text { Lighting - } \\
\text { Luminaire or } \\
\text { Lamp } \\
\text { Switching }\end{array}$ & $\begin{array}{l}\text { Automated lighting controls can } \\
\text { be used to turn off individual } \\
\text { luminaires or lamps within a } \\
\text { lighting fixture during peak } \\
\text { periods. }\end{array}$ & $x$ & & $x$ & & & $x$ \\
\hline
\end{tabular}




\begin{tabular}{|c|c|c|c|c|c|c|c|c|}
\hline $\begin{array}{l}\text { Load } \\
\text { Flexibility } \\
\text { Category }\end{array}$ & \multicolumn{2}{|l|}{$\begin{array}{c}\text { Example GEB } \\
\text { Measures }\end{array}$} & $\begin{array}{l}\text { Load } \\
\text { Shed }\end{array}$ & $\begin{array}{l}\text { Load } \\
\text { Shift }\end{array}$ & $\begin{array}{l}\text { Demand } \\
\text { Response }\end{array}$ & \multirow[t]{2}{*}{ Generation } & \multirow[t]{2}{*}{ Modulation } & \multirow[t]{2}{*}{ Efficiency } \\
\hline \multirow{6}{*}{ 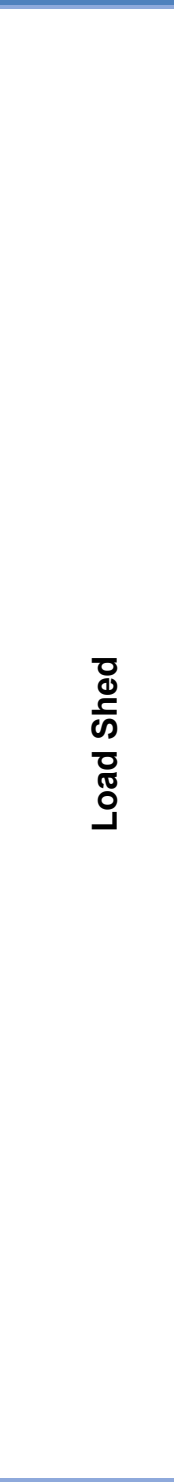 } & $\begin{array}{l}\text { Lighting - } \\
\text { Continuous } \\
\text { Dimming }\end{array}$ & $\begin{array}{l}\text { LED fixtures with continuous } \\
\text { dimming capabilities and } \\
\text { automated controls can be used } \\
\text { to dim lights during peak periods. }\end{array}$ & $x$ & & $x$ & & & \\
\hline & $\begin{array}{l}\text { HVAC - Widen } \\
\text { Zone } \\
\text { Temperature } \\
\text { Bands }\end{array}$ & $\begin{array}{l}\text { During peak periods, zone } \\
\text { temperature setpoints for non- } \\
\text { critical zones can be increased or } \\
\text { decreased (depending on season) } \\
\text { to reduce HVAC demand. }\end{array}$ & $\mathrm{X}$ & & $X$ & & & $x$ \\
\hline & $\begin{array}{l}\text { HVAC - Reset } \\
\text { Supply Air } \\
\text { Static } \\
\text { Pressure }\end{array}$ & $\begin{array}{l}\text { During peak periods, supply air } \\
\text { static pressure for variable air } \\
\text { volume air handling units can be } \\
\text { reset to reduce variable frequency } \\
\text { drive (VFD) speed and electrical } \\
\text { power for HVAC fans. }\end{array}$ & $x$ & & $X$ & & & $x$ \\
\hline & $\begin{array}{l}\text { HVAC - Reset } \\
\text { Supply Air } \\
\text { Temperature }\end{array}$ & $\begin{array}{l}\text { During peak cooling periods, air } \\
\text { handling unit (AHU) supply air } \\
\text { temperature can be reset upwards } \\
\text { to reduce zone cooling loads and } \\
\text { decrease cooling energy. During } \\
\text { peak heating periods, AHU supply } \\
\text { air temperature can be reset } \\
\text { downwards to reduce zone } \\
\text { heating loads and decrease } \\
\text { heating energy. }\end{array}$ & $x$ & & $X$ & & & $X$ \\
\hline & $\begin{array}{l}\text { HVAC - VFD } \\
\text { Limits }\end{array}$ & $\begin{array}{l}\text { During peak periods, VFD speeds } \\
\text { for fans and pumps can either be } \\
\text { limited or decreased by a certain } \\
\text { percentage }\end{array}$ & $X$ & & $X$ & & & $x$ \\
\hline & $\begin{array}{l}\text { HVAC - } \\
\text { Chilled Water } \\
\text { Set Point }\end{array}$ & $\begin{array}{l}\text { During peak periods, chilled water } \\
\text { setpoint can be increased to } \\
\text { reduce electrical cooling load. } \\
\text { Chiller demand or capacity limits } \\
\text { can also be set in the building } \\
\text { automation system (BAS) to limit } \\
\text { demand. }\end{array}$ & $X$ & & $X$ & & & $X$ \\
\hline
\end{tabular}




\begin{tabular}{|c|c|c|c|c|c|c|c|c|}
\hline $\begin{array}{l}\text { Load } \\
\text { Flexibility } \\
\text { Category }\end{array}$ & $\begin{array}{c}\text { Example GEB } \\
\text { Measures }\end{array}$ & GEB Control Capability & $\begin{array}{l}\text { Load } \\
\text { Shed }\end{array}$ & $\begin{array}{l}\text { Load } \\
\text { Shift }\end{array}$ & $\begin{array}{l}\text { Demand } \\
\text { Response }\end{array}$ & Generation & Modulation & Efficiency \\
\hline \multirow{3}{*}{ 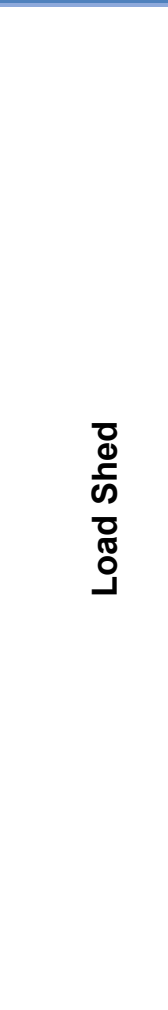 } & $\begin{array}{l}\text { HVAC - Chiller } \\
\text { Staging }\end{array}$ & $\begin{array}{l}\text { During peak periods, the } \\
\text { sequence of operation for chiller } \\
\text { staging can be modified to } \\
\text { operate smaller chillers and turn } \\
\text { off larger chillers to reduce cooling } \\
\text { demand. }\end{array}$ & $\mathbf{X}$ & & $X$ & & & $x$ \\
\hline & $\begin{array}{l}\text { HVAC - } \\
\text { Advanced } \\
\text { Rooftop Unit } \\
\text { (RTU) Controls }\end{array}$ & $\begin{array}{l}\text { During peak periods, RTUs with } \\
\text { advanced controls can limit fan } \\
\text { speed and increase space set } \\
\text { point temperature. For multiple } \\
\text { RTUs with advanced controls, } \\
\text { compressors on the units can be } \\
\text { cycled on and off for } 15 \text { minutes } \\
\text { each to reduce demand. }\end{array}$ & $\mathbf{X}$ & & $X$ & & & $x$ \\
\hline & $\begin{array}{l}\text { Whole } \\
\text { Building - } \\
\text { Energy } \\
\text { Management } \\
\text { Information } \\
\text { Systems }\end{array}$ & $\begin{array}{l}\text { Whole building energy } \\
\text { management information systems } \\
\text { (EMIS) can be used to integrate } \\
\text { all end uses (HVAC, lighting, } \\
\text { plugs) and DER. These systems } \\
\text { typically use machine learning } \\
\text { and model predictive control to } \\
\text { predict day-ahead electrical load } \\
\text { profiles and can be used to shed } \\
\text { load for any building system } \\
\text { connected to the EMIS. }\end{array}$ & $\mathrm{X}$ & $x$ & $x$ & $x$ & $x$ & $x$ \\
\hline
\end{tabular}




\subsection{Load Shift}

Incentives for load shift measures have historically focused on shifting HVAC and water heating loads from on-peak daytime hours to off-peak nighttime hours using thermal energy storage (either ice energy storage or cold or hot water thermal storage). For example, three California utilities launched an incentive program in 2013 called the 'Permanent Load Shift Program' that offered upfront incentives of $\$ 875$ per kilowatt of air conditioning load that was shifted to precool at night, plus ongoing performance incentives over a five-year period. ${ }^{15}$

Although the Permanent Load Shift Program targeted thermal energy storage, any energy storage technology sited behind the meter could be used to perform load shifting. In addition, over the last few years, a number of emerging load shift measures have been deployed such as buildinglevel battery storage and electric vehicles with managed charging to shift onsite electrical loads. For thermal loads, emerging technologies include the integration of phase change materials within rooftop units, AHUs, building materials, and phase change-based thermal energy storage tanks to store thermal energy at night and discharge it during the day. These emerging solutions are becoming more readily available and affordable.

Load shift programs have been around for a number of years and utility incentives for load shift measures are upfront incentives, making the incentive structure potentially more straightforward to integrate into performance contracts. Load shift measures also are less likely to have an impact on interior space conditions or occupant comfort, and should not require any occupant interaction.

For more traditional load shift technologies like ice energy storage, the entire cooling load is typically shifted to nighttime hours, but in some cases the system can be downsized to just offset cooling loads during peak periods. Similarly, sizing electrical battery storage systems is primarily based on economics, and normally smaller peak-shaving batteries are installed that shift only a portion of the electrical loads. Batteries can also be installed to integrate greater amounts of renewable generation and further reduce the site's carbon footprint as economics and incentives permit. A list of applicable GEB measures that generally fall into the load shift category are summarized in Table 3, Typical Load Shift GEB Measures. 
Table 3. Typical Load Shift GEB Measures

\begin{tabular}{|c|c|c|c|c|c|c|c|}
\hline $\begin{array}{l}\text { Load } \\
\text { Flexibility } \\
\text { Category }\end{array}$ & GEB Measure & GEB Control Capability & $\begin{array}{l}\text { Load } \\
\text { Shed }\end{array}$ & $\begin{array}{l}\text { Load } \\
\text { Shift }\end{array}$ & $\begin{array}{l}\text { Demand } \\
\text { Response }\end{array}$ & Generation & Modulation \\
\hline \multirow{5}{*}{ 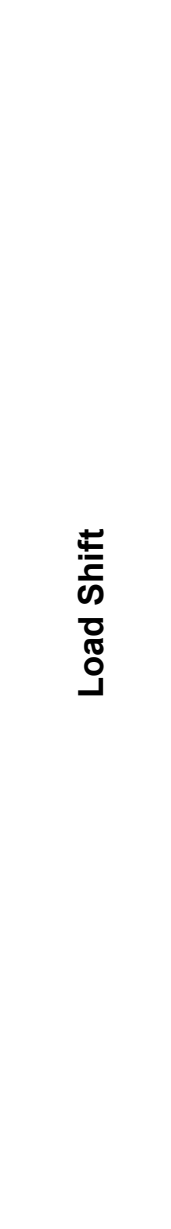 } & $\begin{array}{l}\text { Ice Energy } \\
\text { Thermal Storage } \\
\text { (Direct Expansion } \\
\text { and Chilled Water } \\
\text { Plants) }\end{array}$ & $\begin{array}{l}\text { Ice energy storage can be applied to } \\
\text { both central chilled water plants and } \\
\text { smaller packed direct expansion cooling } \\
\text { systems to shift cooling loads to off-peak } \\
\text { periods. }\end{array}$ & & $\mathbf{X}$ & $X$ & & \\
\hline & $\begin{array}{l}\text { Ice Energy } \\
\text { Thermal Storage } \\
\text { (Refrigeration } \\
\text { Systems) }\end{array}$ & $\begin{array}{l}\text { Ice energy storage can be applied to } \\
\text { large refrigeration systems used for } \\
\text { supermarkets or refrigerated } \\
\text { warehouses. }\end{array}$ & & $\mathbf{x}$ & $x$ & & \\
\hline & $\begin{array}{l}\text { Chilled Water } \\
\text { Thermal Storage }\end{array}$ & $\begin{array}{l}\text { Chilled water storage can be applied to } \\
\text { central chilled water plants to shift } \\
\text { cooling loads to off-peak periods. }\end{array}$ & & $x$ & $x$ & & \\
\hline & $\begin{array}{l}\text { Hot Water } \\
\text { Thermal Storage }\end{array}$ & $\begin{array}{l}\text { Larger hot water storage tanks can be } \\
\text { leveraged to store hot water for longer } \\
\text { periods of time and shift hot water } \\
\text { heating to off-peak periods. }\end{array}$ & & $\mathbf{x}$ & & & \\
\hline & $\begin{array}{l}\text { Phase Change } \\
\text { Material Thermal } \\
\text { Storage }\end{array}$ & $\begin{array}{l}\text { Phase change materials are integrated } \\
\text { into chilled water plants for thermal } \\
\text { energy storage and can also be } \\
\text { integrated into RTUs and building } \\
\text { envelope materials. For building } \\
\text { envelope applications, the buildings are } \\
\text { pre-cooled to charge the thermal energy } \\
\text { storage and reduce daytime cooling } \\
\text { loads. }\end{array}$ & & $\mathbf{X}$ & & & \\
\hline
\end{tabular}




\begin{tabular}{|c|c|c|c|c|c|c|c|}
\hline $\begin{array}{l}\text { Load } \\
\text { Flexibility } \\
\text { Category }\end{array}$ & GEB Measure & GEB Control Capability & $\begin{array}{l}\text { Load } \\
\text { Shed }\end{array}$ & $\begin{array}{l}\text { Load } \\
\text { Shift }\end{array}$ & $\begin{array}{l}\text { Demand } \\
\text { Response }\end{array}$ & Generation & Modulation \\
\hline \multirow{5}{*}{$\begin{array}{l}\frac{ \pm}{c} \\
\bar{c} \\
\frac{1}{0} \\
0 \\
0\end{array}$} & $\begin{array}{l}\text { Building Thermal } \\
\text { Mass Storage }\end{array}$ & $\begin{array}{l}\text { Uses day-ahead weather forecast and } \\
\text { building load profile prediction to pre-cool } \\
\text { building during off-peak hours and } \\
\text { increase occupied cooling setpoint } \\
\text { during peak periods. }\end{array}$ & & $x$ & & & \\
\hline & $\begin{array}{l}\text { Battery Electrical } \\
\text { Storage }\end{array}$ & $\begin{array}{l}\text { Batteries (e.g., Li-ion, lead acid, flow) } \\
\text { can be used to store electrical energy } \\
\text { during times of excess generation or off- } \\
\text { peak periods and discharge during peak } \\
\text { periods to reduce demand. }\end{array}$ & $X$ & $X$ & $X$ & & $x$ \\
\hline & $\begin{array}{l}\text { Electric Vehicles } \\
\text { (EVs) }\end{array}$ & $\begin{array}{l}\text { EVs with managed charging will charge } \\
\text { the connected EVs according to the local } \\
\text { utilities' operational priorities or a grid } \\
\text { signal rather than just charging the EV } \\
\text { when it is plugged in. }{ }^{16}\end{array}$ & & $x$ & $X$ & & \\
\hline & $\begin{array}{l}\text { Data Center - } \\
\text { High Performance } \\
\text { Computing } \\
\text { Scheduling }\end{array}$ & $\begin{array}{l}\text { High performance computing data } \\
\text { centers that are partially loaded can be } \\
\text { scheduled to run tasks that require large } \\
\text { amounts of computing power during off } \\
\text { peak periods. }\end{array}$ & & $X$ & & & \\
\hline & $\begin{array}{l}\text { Domestic Hot } \\
\text { Water - Heat } \\
\text { Pump Water } \\
\text { Heaters }\end{array}$ & $\begin{array}{l}\text { Connected heat pump water heaters can } \\
\text { be scheduled to charge domestic hot } \\
\text { water tanks during off-peak periods and } \\
\text { turn off during peak periods. }\end{array}$ & & $x$ & $x$ & & \\
\hline
\end{tabular}

As the country works to decarbonize both the building and transportation industries, electrification is emerging as a major trend that enables greenhouse gas emissions reductions. As the federal sector works to convert the federal fleet to electric vehicles and agencies install technologies like ground source heat pumps, cold climate heat pumps, and variable refrigerant flow technologies to electrify buildings, onsite electrical loads will increase and the demand for load shed and load shift technologies will increase over time. 


\subsection{Load Modulation}

Load modulation technologies are technologies that can rapidly respond to poor power quality or short-term grid disturbances, with duration and response times typically in the seconds-tosubseconds time frame. Load modulation technologies are not typically incorporated within performance contracts unless they are integrated into larger smart grid initiatives for federal sites with specific resilience, islanding, and distribution system control needs.

One example of a common load modulation technology is smart photovoltaic (PV) inverters that have the ability to manage volt-ampere reactive (VAR) output as a function of incoming grid voltage and can prioritize either power output or VAR output. In addition, smart PV inverters remain connected during brief voltage sags or swells from the incoming grid power, all of which serve as a form of subsecond load modulation. ${ }^{17}$

In addition, other building end-use systems (such as LED lighting, bi-directional EV charging, or certain HVAC equipment like variable air volume fans) also have the potential to help balance the grid by minutely ramping up or down in response to a utility signal. This would require automatic control of the building resources by a utility or other service provider. The communication speed, equipment response time, and ramp rates should also be considered in these circumstances.

Load modulation technologies should be considered on a case-by-case basis and only considered where they are incentivized by the utility or are required for other site-specific microgrid or resiliency requirements.

\subsection{Generation}

Onsite generation can take many forms, such as (1) natural gas and dual-fuel reciprocating engines, (2) combustion turbines and steam turbines, (3) fuel cells, (4) biomass combined heat and power (CHP), (5) PV, and (6) wind turbines. These systems can provide a number of potential benefits to an individual facility or campus, including:

- High-quality, reliable, and potentially dispatchable power

- Low-cost energy and long-term utility cost assurance, especially where electricity and/or fuel costs are high

- Significantly reduced greenhouse gas emissions - for all renewable energy measures and potentially for certain CHP systems

- Peak demand shaving where demand costs are high

- The ability to meet standby power needs when designed for the purpose, especially where utility-supplied power is interrupted frequently or for long periods and where standby power is required for safety or emergencies

- Combining onsite renewable energy generation with load shed and load shift have the ability to significantly reduce carbon emissions from the electric grid during peak periods.

Categories of both load modulation and generation technologies are summarized in Table 4. Onsite generation technologies are commonly installed in performance contracts and 
considerations for onsite generation should be included in discussions with the local utility to understand requirements and potential limitations for connecting to the grid.

The ability for a generator to support load and grid stability depends on the status of the generation at the time of the event. If a generator is online and connected to the distribution network, it can respond quicker to requests or events on the grid. If a generator is offline, it may require 30 seconds to 30 minutes, depending on the size of the generator, to be brought online and to synchronize with the distribution grid to support connected loads and provide modulation services. 
Table 4. Typical Generation and Load Modulation GEB Measures

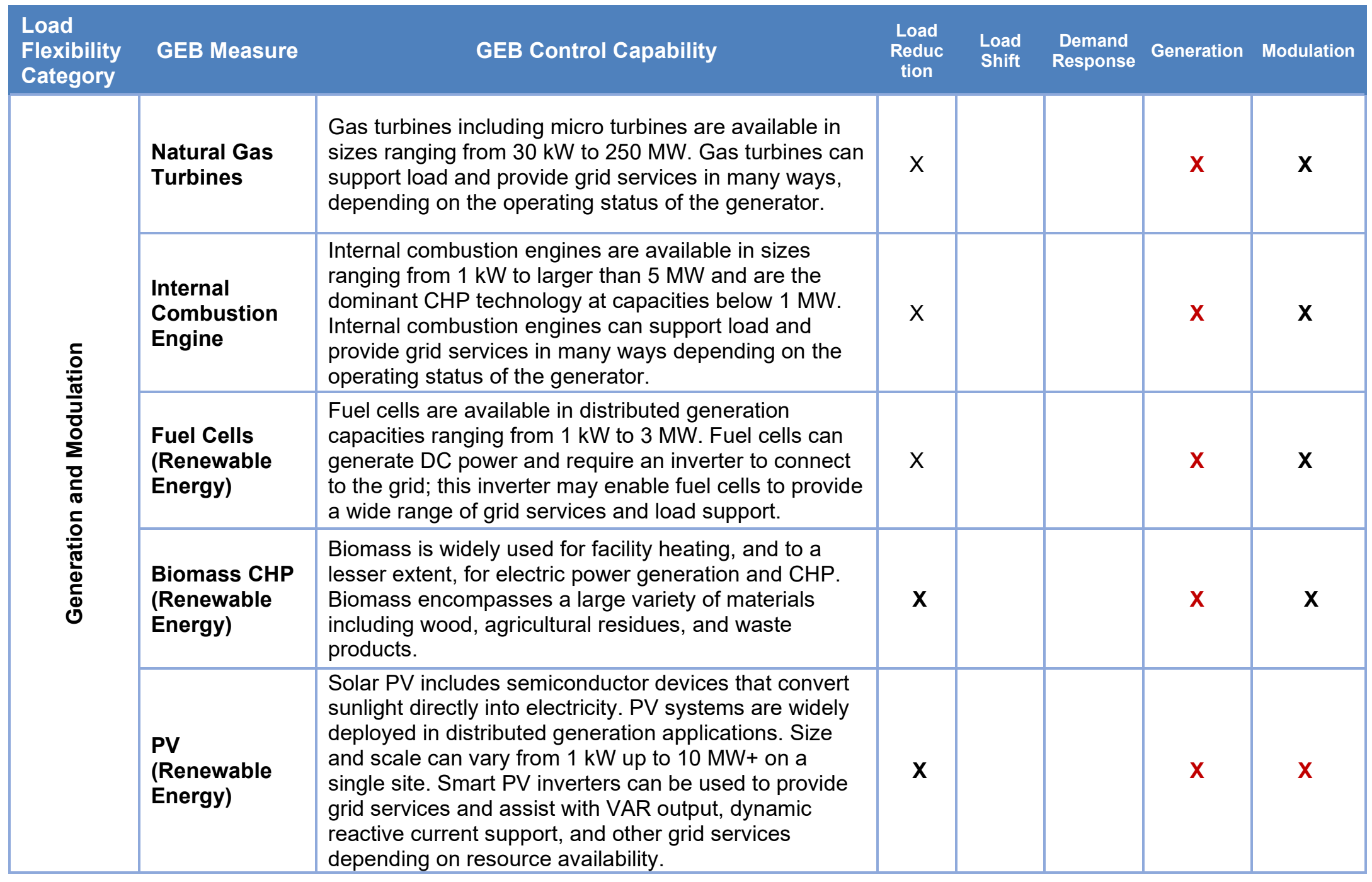




\begin{tabular}{|c|c|c|c|c|c|c|c|}
\hline $\begin{array}{l}\text { Load } \\
\text { Flexibility } \\
\text { Category }\end{array}$ & GEB Measure & GEB Control Capability & $\begin{array}{l}\text { Load } \\
\text { Reduc } \\
\text { tion }\end{array}$ & $\begin{array}{l}\text { Load } \\
\text { Shift }\end{array}$ & $\begin{array}{l}\text { Demand } \\
\text { Response }\end{array}$ & Generation & Modulation \\
\hline & $\begin{array}{l}\text { Wind Turbines } \\
\text { (Renewable } \\
\text { Energy) }\end{array}$ & $\begin{array}{l}\text { Small to medium-size wind turbines typically connect to } \\
\text { the grid through a variety of generator and power } \\
\text { electronic configurations. Type } 3 \text { and } 4 \text { wind turbines } \\
\text { employing inverters can be used to provide grid } \\
\text { services and assist with VAR output, dynamic reactive } \\
\text { current support, and other grid services depending on } \\
\text { resource availability. }\end{array}$ & $x$ & & & $\mathbf{x}$ & $\mathbf{X}$ \\
\hline
\end{tabular}


It is important to note that although these technologies can be installed in isolation, the intent of GEB is to implement multiple GEB measures from different categories to synergistically address load flexibility and reduce peak demand. As a first step, GSA could identify the sites with the highest potential for a GEB project in its portfolio of properties through a vetted, multi-phase screening process.

\section{GEB Challenge \#1: Technology Maturity}

GEB measures can be deployed at the end-use level (lighting, HVAC, plug loads) and/or at the whole-building level through a supervisory control platform that integrates all end-use loads (e.g., BAS, lighting, plugs). This includes the ability to provide GEB control on top of the native control that is built into the BAS, lighting controls, and so forth. The level of technical maturity varies from one end use to another and these technologies are still emerging at the whole-building supervisory control system level.

\section{Recommendations}

The GPG program is evaluating several emerging supervisory control systems for GEB. Once these demonstrations are complete, GSA could share test results and deployment recommendations with energy services companies (ESCOs), utilities, and other federal agencies to increase the positive impact.

For equipment-specific GEB technologies such as advanced LED lighting controls or plug load controls, GSA and the contractor need to ensure the following:

- The GEB technology chosen is proven, available, and appropriate for the potential project

- If there are IoT or connectivity requirements, the GSA information technology team is involved and that the technology has preferably gone through GSA cybersecurity FedRamp process prior to Phase 1 of the performance contract

- Ensure the technology is able to meet GSA P100 requirements and any other relevant GSA standards or requirements.

\subsubsection{Cybersecurity Accreditation}

Cybersecurity has become increasingly important, and federal legislation requires that any technology (including ECMs) with an information technology or operational technology component and that collects, processes, stores, maintains, and use information through an onsite communications network must demonstrate compliance with information security and operational technology requirements for authority to operate (ATO). Cybersecurity ATO is required for all applicable GEB control systems or GEB measures, and all existing or newlyinstalled AMI, BAS, or IoT must also have cybersecurity ATO prior to being connected to a GEB control system or GEB technology.

As directed by the Federal Information Security Modernization Act of 2014, the National Institute of Standards and Technology (NIST) created framework requirements by which 
agencies can manage organizational cybersecurity risk and select the appropriate security controls to protect information and information systems as well as obtain ATOs for those systems under the NIST Risk Management Framework. Executive Order 13800 requires federal agencies to follow a similar framework - the NIST Cybersecurity Framework, which consists of standards, guidelines, and best practices to manage cybersecurity-related risk.

GSA has a list of control systems and devices (e.g., lighting control systems) that have received an ATO, and these control systems and devices should be prioritized for implementation in energy projects in order to avoid project delays to achieve an ATO for a given GEB measure. Additional cybersecurity requirements may apply for specific facilities or to meet tenant conditions.

\section{GEB Screening Process}

GSA is using available data sources to narrow down the group of buildings with the highest potential for deep energy savings and demand flexibility. Important considerations such as impending equipment replacement or significant comfort issues can also help to prioritize a potential retrofit project in conjunction with funding considerations. The project selection process results in a list of high-priority buildings which

In this chapter:

- GSA approach to site screening

- Screening phases

- Utility rate considerations for GEB screening is then reviewed by the regions. The final project selection happens through collaboration between the central office and the region. As such, the screening process outlined below will be used to down-select the top sites for future GSA NDER locations.

GSA manages the single largest portfolio of commercial office space in the country, across 11 regions (shown in Figure 4), making the efficient identification of sites with the highest GEB potential particularly important. The GSA portfolio includes:

- $\quad 8,721$ total properties (377 million $\mathrm{ft}^{2}$ ) under GSA management

- 1,574 GSA-owned properties (188 million $\left.\mathrm{ft}^{2}\right)$

- Annual energy costs of \$280 million per year for GSA-owned real estate. At $52.2 \mathrm{kBTU}$ per square foot per year, GSA buildings are 33\% more efficient than typical U.S. commercial buildings. ${ }^{18}$ 


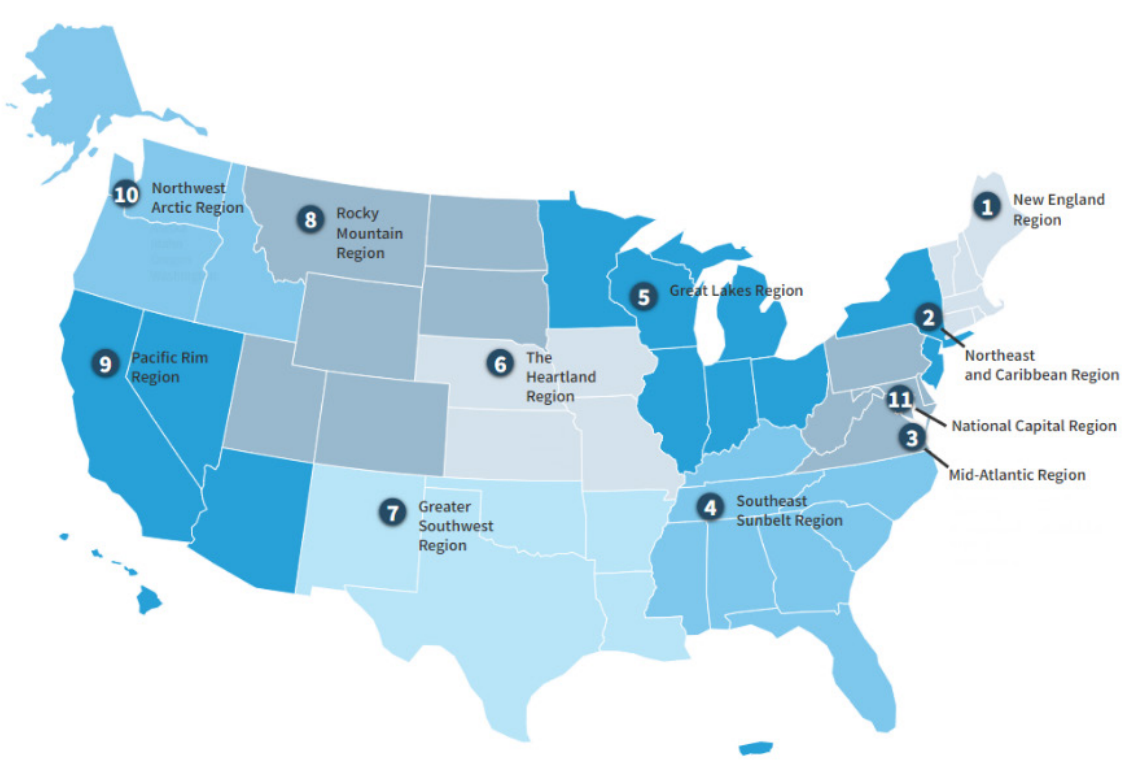

Figure 4. GSA region map ${ }^{19}$

Image Credit: GSA

The purpose of a site screening approach is to efficiently apply resources to the sites with the highest probability of a cost-effective GEB project, and rule out sites with minimal probability of a cost-effective project. A multi-phase screening process could help GSA to incrementally narrow its broad portfolio of sites down to a prioritized list of sites with high potential for GEB success. This process has been successfully implemented in prior efforts supporting DOE in screening for large-scale renewable energy projects, ${ }^{20}$ and the Department of Defense in screening for cost-effective behind-the-meter battery storage.

Early review of the availability of data across GSA's portfolio is a critical first step to defining this analysis. GSA previously screened roughly 200 sites for their renewable energy potential, which may provide data that could help inform this GEB screening as well. Table 5 and Figure 5 summarize this multi-step screening process. 
Table 5. Multi-Phase GEB Screening Process

\begin{tabular}{|c|c|c|c|c|}
\hline & Screening Phase & Description & Data Needs/Considerations & Sites Included \\
\hline 1 & Market Screening & $\begin{array}{l}\text { Market-based } \\
\text { screening utilizing } \\
\text { existing datasets }\end{array}$ & $\begin{array}{ll}\text { - } & \text { Site locations } \\
\text { - } & \text { Site consumption } \\
\text { - } & \text { Blended electricity rate } \\
& \text { Presence of utility incentive } \\
& \text { programs }\end{array}$ & - GSA portfolio \\
\hline 2 & $\begin{array}{l}\text { High-Level DER } \\
\text { Screening }\end{array}$ & $\begin{array}{l}\text { High-level DER } \\
\text { screening } \\
\text { incorporating site- } \\
\text { specific utility rate }\end{array}$ & $\begin{array}{l}\text { - Type of existing electric rate } \\
\text { - } \quad \text { connual electricity } \\
\text { consumption (hourly } \\
\text { simulated and scaled) }\end{array}$ & $\begin{array}{l}\text { Start with top } \\
\text { sites from } \\
\text { previous GSA } \\
\text { analysis for } \\
\text { which copy of bill } \\
\text { can be obtained }\end{array}$ \\
\hline 3 & $\begin{array}{l}\text { Detailed GEB } \\
\text { Analysis }\end{array}$ & $\begin{array}{l}\text { In-depth energy } \\
\text { modeling analysis at } \\
\text { top sites; will require } \\
\text { additional data from } \\
\text { sites. }\end{array}$ & $\begin{array}{l}\text { 15-minute electrical meter } \\
\text { interval data from site } \\
\text { - Custom modeled utility rate } \\
\text { Additional building data and } \\
\text { existing BAS and control } \\
\text { system data, LED lighting, } \\
\text { and plug load data }\end{array}$ & $\begin{array}{l}\text { Prioritized list of } \\
\text { high potential } \\
\text { sites }\end{array}$ \\
\hline
\end{tabular}

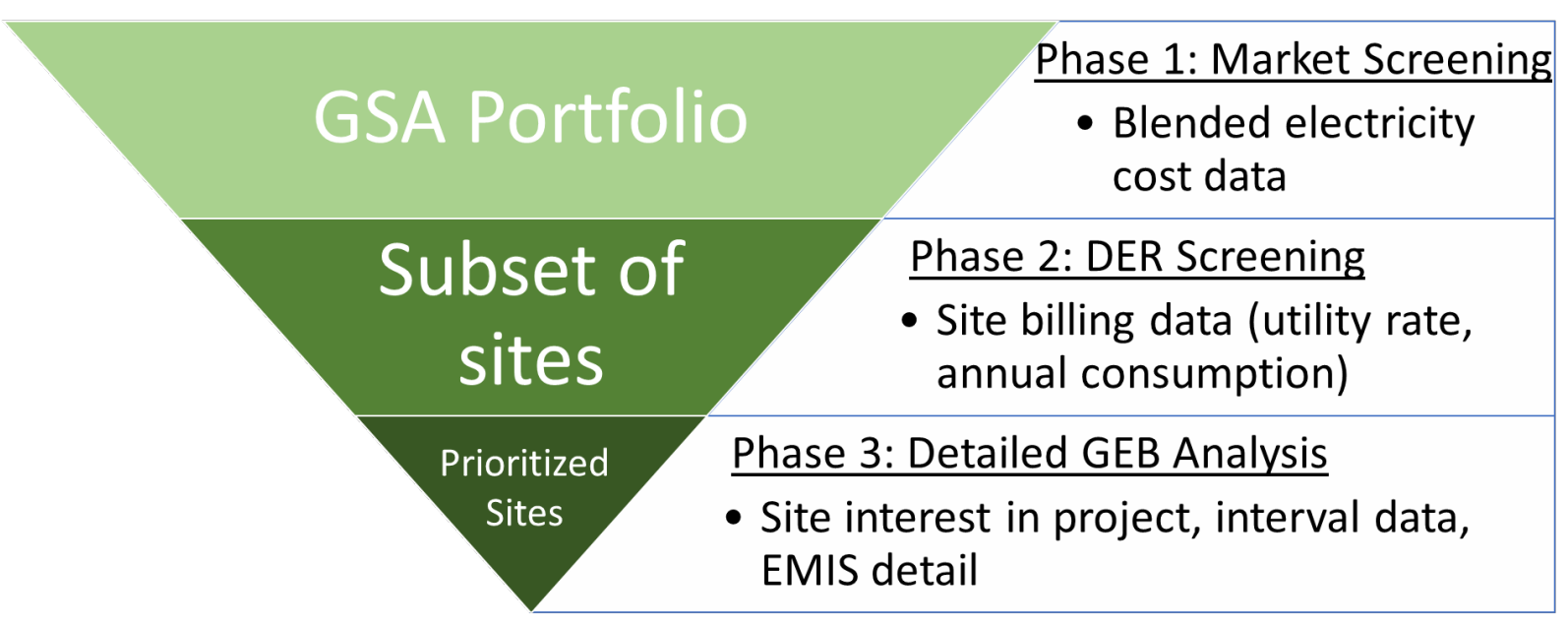

Figure 5. Multi-phase GEB screening overview

Image Credit: Doug Gagne, NREL

The first phase, Market Screening, would involve a market-based screening of all GSA sites with the required blended utility cost information. This step could leverage a prior nationwide NREL analysis of utility rates by county to rule out sites with very low electricity costs and minimal incentives that would be unlikely to be cost-effective. These blended rates and incentives could be ranked and scored and sites scoring above a certain cutoff could advance to the second phase.

The second phase, High-Level DER Screening, would require additional information from the selected sites, including actual (not blended) utility rates and annual electricity consumption data. This data could be incorporated into NREL's REopt model, which is a mixed-integer linear 
optimization program used for techno-economic analysis of renewable and conventional generation, energy storage, dispatchable loads, and energy efficiency to meet cost savings and energy performance goals. ${ }^{21}$

Phase 3 would include evaluation and prioritization of a short list of promising sites in much greater detail, requiring additional site data and engagement. Sites that are already considering large capital investments to upgrade energy systems could also be included in this stage of analysis to ensure that opportunities are not missed.

- Sites would ideally need to provide hourly or 15-minute data at the revenue meter level, which may require individual outreach to each location

$\circ$ Locating and obtaining consistent advanced metering infrastructure (AMI) interval data is critical to GEB analysis. The shape of the load profile will determine many GEB value streams (e.g., reduction in peak demand, TOU consumption)

- Non-technical considerations such as site interest and presence of staff who could champion the project

- Successful GEB solutions will require continuous management of peak loads and well-defined partnerships with the local utility to ensure the selected GEB solutions are providing grid services that are needed and incentivized by the serving utility

- Additional building data, existing control system information, and other information may be required to successfully model GEB opportunities.

\subsection{Utility Rate Considerations for GEB Projects}

There are thousands of utility rate tariffs throughout the United States, so careful evaluation of a tariff's favorability for both GEB and other ECMs is essential. Following are some factors for evaluating the favorability of local utility rates for GEB projects.

Utility tariffs commonly break out their charges into two general categories: energy charges and demand charges. Energy charges are billed based on a site's consumption of electricity over time (in dollars per kWh), whereas demand charges are typically based on a site's highest 15-minute rate of consumption (in dollars per $\mathrm{kW}$ ) within a month.

In general, sites with utility rates that charge heavily for peak demand, have large differences between peak and non-peak energy and demand charges, or offer TOU rates with high on-peak charges can make GEB projects more cost effective. Under these tariffs, the GEB measures' ability to shift load away from expensive periods of the day (high peak demand or on-peak periods) generates the highest amount of savings. However, the site's hourly demand profile is extremely important as well, as discussed further in Section 5.3.2, Preliminary Assessment Requirements. As one potential indication of viability, GSA site locations are shown in relation to regional demand rates in $6 .^{22}$ Rates that are favorable for GEB projects are still relatively rare nationwide, and are predominantly located in states like California, Utah, Florida, and New York, which all appear to contain multiple GSA sites with demand rates above $\$ 20$ per kWthese may be promising areas for early exploration. 


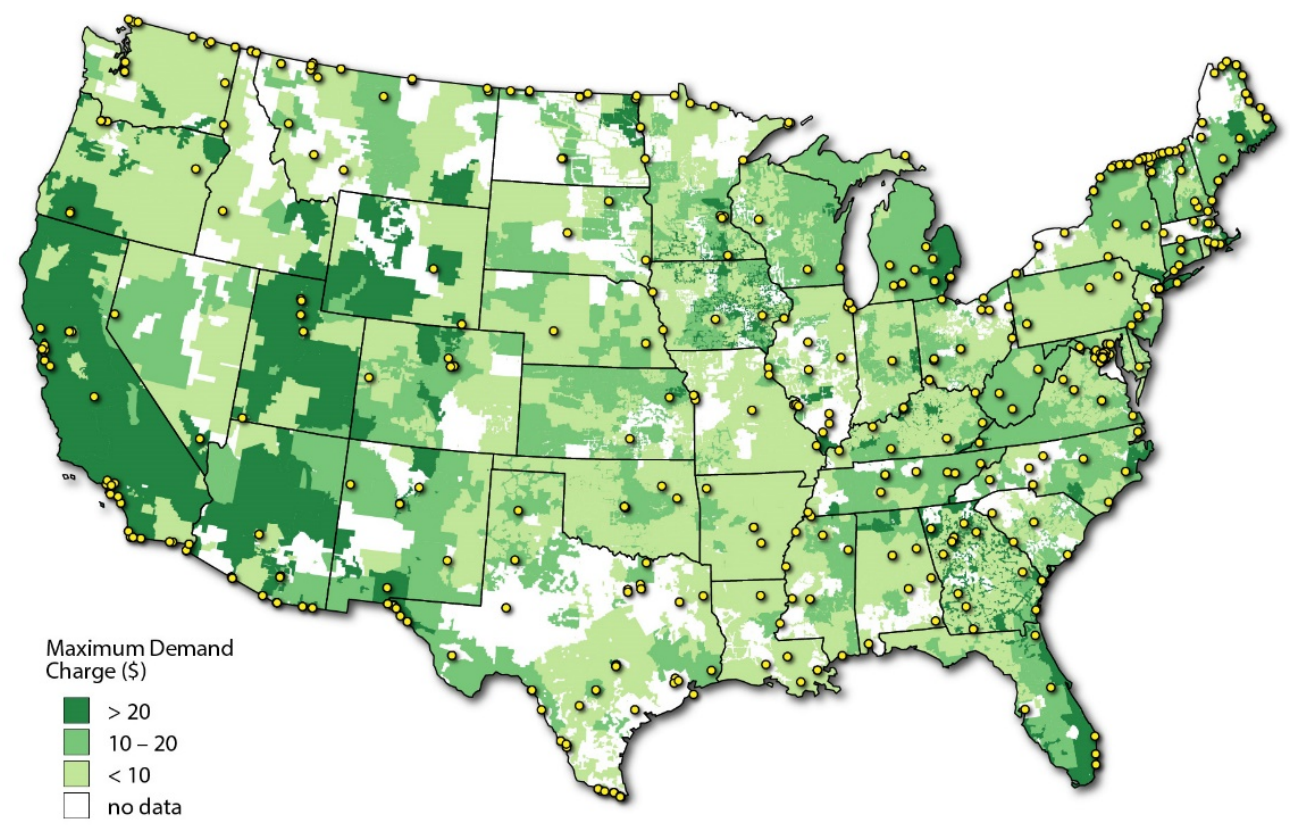

Figure 6. National demand charge rates and GSA site locations

Image Credit: Billy Roberts, NREL

Conversely, unfavorable rates for GEB are those that do not reward this ability to shift load (e.g., flat energy rates at all hours, rates with low energy and demand costs). Other rates, such as those with high demand charges but low energy charges or high TOU differentials, may be viable for a GEB project, but could result in lower cost savings for other ECMs in a performance contract. Other utility purchase structures common with federal sites, such as electricity supply contracts and block and index pricing structures, may also make GEB projects challenging due to low energy prices and fixed rates. Table 6 shows which rate structures are generally most likely to be favorable for a GEB project, with illustrative examples of charges in each category. This table only implies that a tariff with high GEB favorability is more likely to be cost-effective, but sitespecific cost and development considerations will play an equally important role in determining project feasibility.

Table 6. Illustrative Utility Rate Favorability for GEB

\begin{tabular}{|l|c|c|c|}
\hline Rate Type & $\begin{array}{c}\text { GEB } \\
\text { Favorability }\end{array}$ & $\begin{array}{c}\text { Total Energy } \\
\text { Charges }\end{array}$ & $\begin{array}{c}\text { Total Demand } \\
\text { Charges }\end{array}$ \\
\hline $\begin{array}{l}\text { Low energy and } \\
\text { demand rates }\end{array}$ & Less & $\$ 0.05-0.10 / \mathrm{kWh}$ & $\$ 5-\$ 10 / \mathrm{kW}$ \\
\hline $\begin{array}{l}\text { High demand rate } \\
\text { (low energy rate) }\end{array}$ & More & $\$ 0.05-0.10 / \mathrm{kWh}$ & $\$ 10-\$ 20 / \mathrm{kW}$ \\
\hline $\begin{array}{l}\text { High demand rate } \\
\text { (high energy rate) }\end{array}$ & Most & $\$ 0.10-\$ 0.20 / \mathrm{kWh}$ & $\$ 10-\$ 20 / \mathrm{kW}$ \\
\hline
\end{tabular}

Note that the presence of a less, more, or most favorable rate structure does not guarantee a successful nor unsuccessful project as there are many additional utility tariff riders and 
restrictions that could benefit or work against a project. GSA should consider whether one or more of the following circumstances apply.

- State, local, and utility incentives: The presence of incentives can be a crucial driver of a GEB project. Many utilities offer rebate programs for common ECMs such as lighting, HVAC retrofits, and more efficient appliances, and may provide for customized incentives for GEB measures as well. ${ }^{23}$ Federal leadership could help utilities to develop prescriptive rebates for specific GEB technologies and drive further adoption.

- Demand response programs: Some utilities and wholesale markets such as PJM and the California Independent System Operator (CAISO) offer programs that compensate customers for changing the amount and timing of their electricity use. These programs vary widely in their details, but generally involve a certain number of demand response events during which the utility will request that the customer lower their load by a specific amount during periods of high demand on the utility's system. ${ }^{24} \mathrm{~A}$ trend towards increasing electrification in many utility territories may increase the value and importance of these programs for GEB applications.

- Coincident peak demand charges: Similar to demand response, certain utilities and markets pass their coincident peak costs on to customers in the form of coincident peak demand charges. These are typically established based on the customer's demand during the highest (coincident) system-wide peak rather than the highest customer demand interval during the billing cycle. Predicting these peaks typically involves advanced forecasting and analytics and may require a third-party vendor to provide this service, but could offer a significant GEB savings opportunity. Some utilities also offer incentives for GEB technologies that reduce consumption during their coincident peak times.

- Virtual power plant/aggregator laws: For certain states, such as California, laws may allow the inclusion of a site's GEB measures within a broader, aggregated portfolio managed by an entity like a community choice aggregator. This could allow a facility to gain additional revenue by providing grid services like capacity or frequency response.

- Minimum billing demand clauses: Some utility rates may include minimum billing demand clauses that make it harder for GEB projects to generate demand savings. These can be simple clauses that specify a minimum billing demand that will be charged regardless of the site's consumption, or more complex clauses that base the minimum demand on a percentage of the site's highest demand over the past 12 months.

For additional information on utility rates and their impacts on GEB projects, see ASHRAE's Smart Grid Application Guide: Integrating Facilities with the Electric Grid. ${ }^{25}$ 


\section{Implementing GEB Using Energy Performance Contracts}

After high-potential GEB sites are identified using the screening approach described in Section 4, funding will be needed for implementation. If appropriated funds are not readily available, GSA could implement GEB measures as part of an energy efficiency, renewable energy, and/or deep energy retrofit project using an energy performance contracting approach.

Federal agencies use energy performance contracts to obtain infrastructure improvements for energy and water efficiencies and renewable energy generation by implementing life-cycle cost-effective ECMs that generate cost savings sufficient to pay for their design and installation. GSA has multiple acquisition methods available to accomplish program and project objectives, priorities, and requirements. Pursuant to 42 U.S. Code (U.S.C.) § 8287 - Authority to enter into contracts and 42 U.S.C. $§$ 8256 - Utility incentive programs, GSA may implement GEB measures and build GEB readiness using, respectively, an ESPC or a UESC.

Performance contracting is a proven strategy that has been widely used by GSA. During the implementation phases of the NDER program, GSA used the DOE ESPC indefinite delivery indefinite quantity (IDIQ) contract to meet deep energy savings objectives. GSA is now working to integrate NDER and GEB strategies, leveraging available appropriations in combination with ESPCs and UESCs to maximize energy and cost savings and greenhouse gas reductions for both retrofit and renovation projects nationwide.

This section describes common performance contracting approaches, challenges, and contractual considerations pertinent to GEB, and best practices and recommendations for each phase of performance contract development and implementation.

\subsection{Energy Performance Contracting}

Both ESPCs and UESCs are contracts between a federal agency and an eligible contractor. In both types of agreement, a contractor provides analysis and engineering, design and installation, and functional testing and commissioning to deliver a full-service, self-funding, and performance-proven set of measures to meet the objectives and priorities of the customer. ESPC and UESC projects can also provide the related operations and maintenance $(\mathrm{O} \& \mathrm{M})$, repair, and recommissioning of the installed measures over the term of the contract.

The ESCO or utility provides financing for ECM design and implementation, and is then paid from annual cost savings generated by the project over a maximum contract term of 25 years. Existing legislation allows for an agency to use a combination of appropriated funds and financing to pay for the project, providing useful flexibility. However, an agency may have limiting guidelines such as a requirement that appropriations applied must be for the purpose of 
energy-related projects. There may also be timing limitations, such as when appropriations approvals do not match up with performance contracting project timelines. ${ }^{26}$

\section{Performance Contracting Basics}

\section{Energy Savings Performance Contract}

An ESPC is a competitively-awarded contract between a federal agency and an ESCO to procure energy, water, and related savings and facility improvements, with streamlined approaches to satisfy the competition requirement. Comprehensive ESPCs can be implemented using the DOE ESPC IDIQ contract, or projects with simple, straightforward ECMs can use the ESPC ENABLE vehicle on the GSA Supply Schedule SIN 334512. The ESCO is responsible for O\&M and repair and replacement of installed ECMs, although those specific activities may be performed by agency staff. As required by legislation, annual energy savings and performance are guaranteed and verified through specific measurement and verification $(\mathrm{M} \& \mathrm{~V})$ procedures as agreed upon in the $\mathrm{M} \& \mathrm{~V}$ plan, and payments may not exceed savings in any year of the contract term.

\section{Utility Energy Service Contract}

A UESC is a limited-source contract between a federal agency and serving electric, natural gas, or water utility for energy management services including energy and water efficiency improvements and energy demand reduction. In addition to the infrastructure-improving ECMs, the scope of a UESC must include a performance assurance plan which will provide the instruction, the details, and the negotiated services to prove each measure is performing according to design specifications and to demonstrate the associated savings through commissioning prior to project acceptance. Further, the performance assurance plan must include comprehensive training to prepare the agency to effectively and proficiently sustain the performance and savings of each ECM for the life of the contract. Savings and performance guarantees are negotiable, and it is the intent that savings are greater than payments over the contract term.

Both performance contracting approaches follow five phases of project development and implementation, as shown in Figure 7. Best practices and recommendations regarding how to integrate GEB opportunities into each phase of performance contract development and implementation are discussed in the proceeding sections. 


\section{Phase 1 - Acquisition Planning}

\section{Phase 3 - Utility/Energy Services Company Selection and Preliminary Assessment}

\section{Phase 3 - Pre-Award Project Development}

\section{Phase 4 - Project Implementation}

\section{Phase 5 - Post-Acceptance Performance}

Figure 7. Performance contracting phases

Image Credit: FEMP

\subsection{Phase 1: Acquisition Planning}

Performance contracting efforts typically begin with an agency or site determination that energy equipment upgrades are needed and that appropriations are not sufficient to cover the feasibility study, design and engineering, and implementation costs. An acquisition team is then assembled to discuss procurement approaches and select a performance contracting method for accomplishing the work. Specific ECMs or strategies do not need to be

\section{Phase 1 tasks:}

- Establishing GEB considerations and objectives

- Planning meeting topics

- Stakeholder engagement determined at this time. The planning phase is to discuss and document agency requirements and opportunities to consider in a performance contract and is an optimal time to discuss inclusion of GEB measures in the project.

While energy and water efficiency goals are being developed as part of the acquisition planning phase, GEB considerations and objectives should also be established among the agency acquisition team. Acquisition team members should be educated on the GEB concept, at least at a high level, to understand the approach, types of technologies, potential tenant impacts, and considerations for savings verification approaches. As with any performance contracting project, the project champion will lead the overall project efforts and should be well informed on the 
GEB concept. Some GEB-related agenda items and discussion topics for acquisition planning meetings include:

- Staff education on GEB concepts, benefits, and applications

- GEB-related project objectives and priorities

○ How will GEB priorities or "wish list" items enhance the overall project?

$\circ$ Will initial agency screening be needed (facility selection), or has a screening been completed? If screening is already done, share and discuss results.

- Potential gaps between current O\&M practices and those that will be required for GEB technologies - for example, O\&M responsibilities for HVAC load shift measures that should be understood and discussed with the group. This is a general discussion, as the specifics of GEB measures will only be learned during Preliminary Assessment (PA) and Investment-Grade Audit (IGA) development

- The importance of M\&V and performance assurance should be discussed (such as agency expectations and needs); this is a general discussion as more specifics will be developed during PA and IGA phases

- Tenant briefings (when/what/who) and feedback on the overall GEB concept - Discuss when tenant representatives will be briefed on or involved in the project development process

- Information needed from utilities, and the responsible utility contacts (typically account representatives)

- An initial screening, as outlined in Section 3, can inform acquisition planning, help manage expectations, and determine whether the GEB concept should be included in the Notice of Opportunity (NOO). However, keep in mind that the utility or ESCO will perform more detailed analysis during project development, so it is not necessary to determine specific GEB measures at this time.

\subsubsection{Stakeholder Engagement}

In addition to the agency customer, the stakeholders involved in a federal performance contract of this nature are (1) the building tenants and onsite building operational staff, (2) the ESCO, and (3) the serving electric and natural gas utilities. Stakeholder engagement including understanding and acceptance of GEB strategies is important to project success and should occur at various times throughout the project. NREL worked with GSA to integrate GEB measures into a recent UESC project and RMI used feedback from stakeholders involved in this project to develop standardized questionnaires for each stakeholder group. These should be referenced for specific recommendations regarding stakeholder engagement. The recommended stakeholder engagement touch points for each phase of the contract are listed below, and should be agreed upon upfront during the acquisition phase:

a) Include a high-level meeting during the PA to brief the stakeholders on the GEB concept. It is recommended that this be provided as a single webinar to all stakeholders, focused on project goals and GSA's desired outcomes of the GEB analysis that will be conducted during the PA, with time for discussion of stakeholder feedback and concerns. GSA can facilitate any stakeholder discussion with building tenants as well as meetings with the utility and ESCO to explore options for GEB strategies. 
b) During the IGA, when GEB measures are better defined, a more in-depth stakeholder meeting and larger workshop with all stakeholders should be conducted to provide greater detail regarding GEB strategies. During this phase of the contract, review all GEB measures with the group to discuss pros and cons of each measure, and work with onsite staff and tenants to understand any tenant impacts and concerns. During the IGA phase, GSA should require that GEB measures be demonstrated in onsite mockups for any measures that may require tenant approval (such as light dimming or plug load controls).

c) During phases four and five (installation phase and performance period phase), inform stakeholders of installation schedules to minimize tenant impact. Coordinate stakeholder feedback and approvals as needed. The standard stakeholder engagement and trainings that are provided during these phases can be followed and slightly modified to include GEB ECMs as required.

\subsection{Phase 2: Contractor Selection and Preliminary Assessment}

In this phase, GSA can select a utility or ESCO to investigate the opportunity for energy and water efficiency improvements, and GEB goals for the site(s) should be considered in the selection process. The selected contractor will work with GSA to determine facilities that should be screened for GEB measures,

\section{Phase 2 tasks:}

- Notice of opportunity

- Preliminary assessment planning, performance, and reporting develop rough cost and savings estimates for those measures, and identify which measures warrant further investigation. Ideally, a utility or ESCO with GEB implementation experience will be selected.

\subsubsection{Notice of Opportunity with GEB Requirements}

Contractor selection will be accomplished by issuance of a NOO, which provides a general description of the project site(s) and agency objectives, followed by an agency evaluation of interested contractor responses to the NOO. The NOO will be issued either to qualified utilities (for UESCs) or ESCOs (for ESPCs). Providing a table of current energy and demand rates, total electric and water use, utility costs, and site objectives for energy and water efficiency, renewable energy, and GEB strategies in the NOO will result in better responses. Some suggestions for incorporation of GEB requirements in the NOO are listed below.

- Include a description of GSA objectives for GEB in the project, including the site's priorities for investigating and implementing GEB measures. Examples of objectives may include determining feasibility of GEB measures by:

○ Maximizing energy efficiency and cost savings through load flexibility

○ Exploring opportunities for facility load shed, shift, and/or modulation

- Providing a study of renewable energy and energy storage opportunities

- Identifying and applying utility incentives applicable to GEB strategies. 
- Request that the utilities or ESCOs provide a description of their experience with GEB implementation in past projects. Particular emphasis should be placed on their experience with DER, advanced lighting, plug load and HVAC controls, and EMIS.

- Request that the utilities or ESCOs describe their approach to verifying savings from GEB measures with variable savings like demand response (including guaranteed savings for ESPCs).

- State that GEB opportunities beyond those listed in the NOO may be implemented in the future. This will allow the selected utility or ESCO to implement additional GEB measures that they uncover during project development.

- Include any cybersecurity requirements that may be unique to the site. Any ECM, control system, or device connected to the site communications network must meet cybersecurity requirements and go through an ATO process, and these requirements may be more stringent if remote connectivity is allowed (i.e., utility remote control of on-site demandresponse measures). FEMP's "Cybersecurity Considerations for Performance Contracts" offers cybersecurity considerations and additional resources. ${ }^{27}$

\subsubsection{Preliminary Assessment Requirements}

\subsubsection{Preliminary Assessment GEB Analysis Recommendations}

Once the utility or ESCO has been selected, they will work with the agency to conduct high-level walk-through energy audits of select facilities and will create a list of energy and water conservation measures, including GEB measures, that are recommended for further consideration and development. This PA activity is a scoping effort to determine which GEB measures should be considered for more detailed analysis in the later IGA phase. 
The PA should include an analysis of GEB opportunities across the portfolio of sites and buildings considered for the planned performance contract. This involves an investigation of available incentives, building load factors, analysis of energy and water conservation measures, causes and timing of peak electric demand and how these may be reduced, and GEB software integration considerations.

\section{GEB Challenge \#2: Impact from Demand-Centric Rates}

GSA sites will often be able to choose between different electric rate or tariff structures. Many electric utilities are rolling out GEB-favorable TOU rates, where pricing is highest during hours of high demand on the utility's system, and day-ahead pricing, where the electric rates change every hour of the day and every day of the year. Sites will normally select the tariff with the lowest monthly utility cost for the site, but GEB projects introduce a tradeoff in this rate selection process. Utility tariffs with high demand charges but low energy charges may be better for a GEB project but could increase overall site costs and result in less savings for other ECMs in a performance contract.

\section{Recommendation}

GSA is encouraged to require a comparative tariff analysis within their performance contracts and ensure that the tariff that is selected maximizes annual energy cost savings for the entire suite of ECMs in the contract while also incentivizing integration of GEB measures into the project. This comparative analysis should begin early, ideally in the PA phase, to best inform the GEB measure selection and development process.

The PA report will include which GEB measures appear to be cost effective and are recommended for further analysis in the IGA, or are not recommended due to cost or technical factors. It will also include an overview of the utility or ESCO project management approach, technical descriptions and assessments of each measure analyzed, an O\&M strategy, and an $\mathrm{M} \& \mathrm{~V}$ or performance assurance overview for each measure. Estimated costs for implementation and performance period services will be compared to savings estimates to determine which measures to further investigate in the IGA. The PA stage typically also includes an initial utility rate structure and grid services analysis. For specific recommendations and steps related to utility rate analysis, see Appendix A.

Below are several detailed GEB analysis steps that could be conducted during the PA stage to assist in decision making on which measures to pursue.

\section{Quantify GEB Opportunity through AMI Data Collection and Analysis}

During the PA phase of the project, interval meter data (15-minute to 1-hour electrical meter data) is typically not collected and analyzed. For performance contracts in which GSA wants to integrate GEB measures, local GSA staff are encouraged to collect 15-minute to 1-hour electrical meter data for as many buildings and campuses as possible. This interval meter data should be provided to the ESCO so that they understand the weekday and weekend hourly load profiles for the buildings or campus and how they change both monthly and seasonally. A recent GSA ESPC project illustrates the value of this type of data collection and sharing with the ESCO or utility. 
The site has an inverted load profile, shown in Figure 8, with the peak load happening at night and lowest loads during the day from 7 a.m. to 4 p.m.

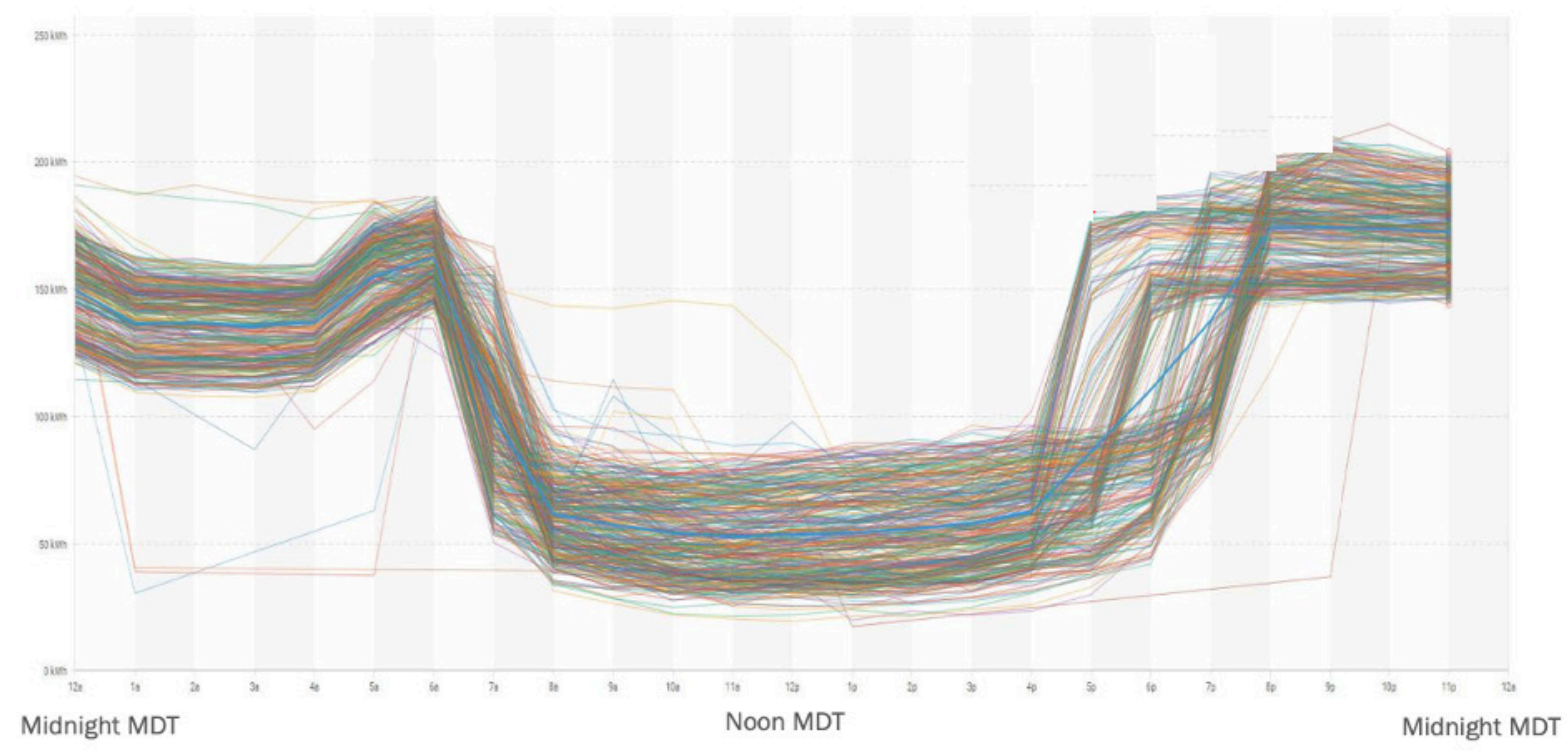

Figure 8. Example inverted electrical load profile

Image Credit: Jesse Dean, NREL

The exterior lighting loads, the largest electrical loads, drive the nighttime peak demand. In this case, GSA worked with the ESCO to identify more efficient LED lighting and battery storage as a viable option to reduce the nighttime demand. This quick AMI load profile screening can be very useful in focusing IGA activities on the most promising candidate sites and GEB solutions.

In another example from a GSA UESC project in 2019, a GSA building has TOU rate from 2 to 7 p.m. and the building's typical weekday electrical load profile for that period is highlighted in yellow in Figure 9. The majority of daytime loads represented in Figure 9 are lighting and plug loads as the heating and cooling for the building is supplied by an offsite central plant and there are fewer opportunities to reduce demand during this period than in other GSA buildings in this region. 


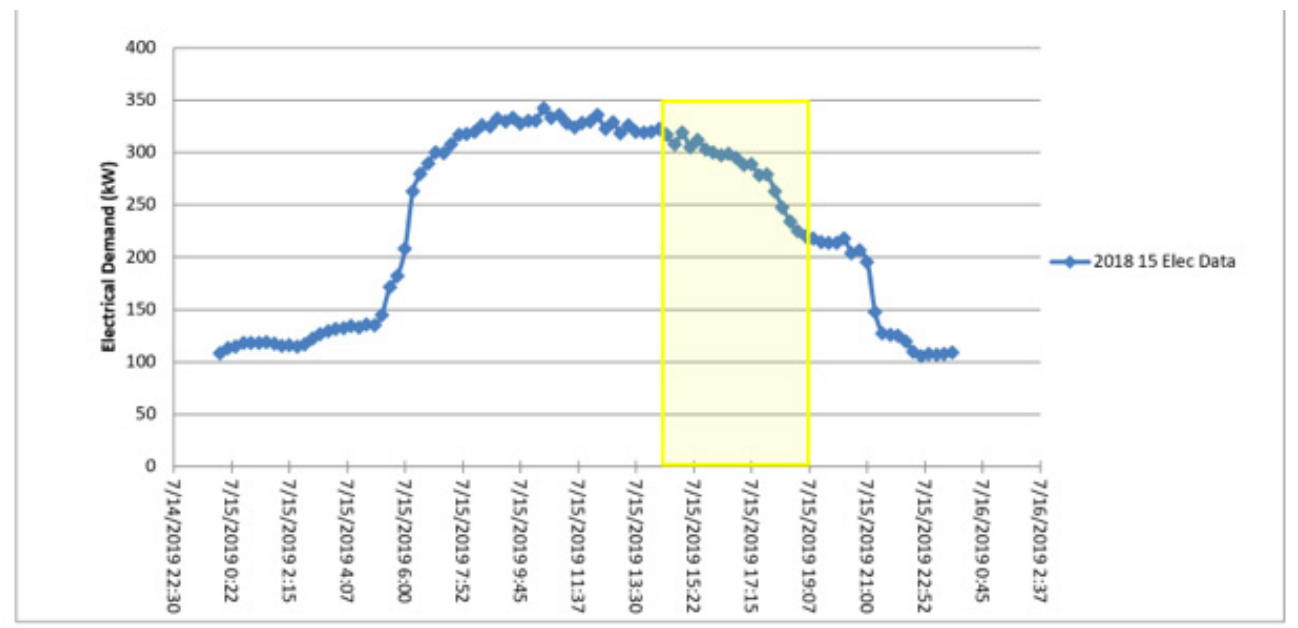

Figure 9. GSA office building electrical load profile

Image Credit: Jesse Dean, NREL

Given that the TOU period is close to the end of the workday for the building, the only options for implementing load shedding to reduce demand during this time are to (1) dim lights at the end of the day, (2) cycle laptop computer batteries at the end of the day (for GSA owned laptops), or (3) ramp down HVAC AHUs during this time.

For this building, any one of the three options could negatively impact interior thermal comfort and occupant satisfaction. The GEB potential for this building is limited due to (1) the peak demand TOU period, (2) the shape of the load profile during the TOU period, and (3) the building's lack of onsite heating or cooling loads that could be shed or shifted.

Recommendations for interval meter data analysis during the PA phase of the project are:

1. Analyze 15-minute electrical load profile data for weekdays, weekends, holidays, and seasonally to capture both heating and cooling system impacts on the load profile for as many buildings and sites as possible. The electrical load profile should be compared to the TOU pricing periods to understand total demand reduction or demand response potential as it relates to highest priced TOU period, etc.

2. Buildings or site electrical load profiles with the following characteristics should be targeted:

a. High peak demand relative to base electrical load or nighttime load (either summer air conditioning load or winter electric resistance heating loads)

b. Air conditioning or chiller loads with peaks that could benefit from optimized HVAC control sequences or would be a good fit for thermal or electrical battery storage to shift loads

c. Electric heating loads that result in high winter peak demands that could be better controlled through GEB strategies

d. Other onsite HVAC systems that are contributing to the peak demand (e.g., data center HVAC systems, kitchen exhaust fans).

3. Buildings or sites with inverted load profiles, very high load factors, flat electrical load profiles, or electrical peaks that are non-coincident with the TOU rate period should be 
avoided.

4. Verify that any buildings under consideration are individually metered for the purpose of determining billing demand. Some sites measure billing demand at the substation, which would allow other site loads to potentially eliminate the anticipated savings.

\section{Prioritization of Sites and Buildings}

The utility or ESCO will evaluate the existing building systems and how they are being used in order to estimate the potential for demand reduction and the impact of potential load shedding, shifting, and/or modulation. Evaluation should always begin with existing building systems to determine if and how they can be modified to support GEB strategies. The addition of load reduction ECMs, new controls and software to support load shed, energy storage technologies to support load shifting, and onsite generation technologies should all be considered relative to existing building type, conditions, and load profiles. A few best practices that can be applied to building selection (for GSA office buildings and courthouses) are:

- The contractor is encouraged to describe how end-use load profiles were used to identify end-use loads with greatest load flexibility potential for both load shed and load shift measures.

- Ensure that HVAC systems are located onsite and are not served by offsite chilled water or steam plants that are owned and operated by a third-party entity (e.g., non-GSA-owned central plants). For GSA sites that are served chilled water and hot water from offsite or nonGSA-owned central plants, the onsite electrical loads will be limited to lighting loads, plug loads, pumps, and motor loads for AHUs and will be significantly lower than the electrical loads of similar buildings with onsite heating and cooling loads.

- Regarding GSA campuses with central chilled water, hot water, or steam plants that serve multiple buildings, these systems are recommended for GEB measures as long as they are owned/operated by GSA and any GEB-related savings can be realized by GSA.

- If heating and/or cooling loads are currently served by offsite plants, replacing those plants with onsite chilled water plants, onsite boiler plants, or onsite variable refrigerant flow systems can be evaluated as potential ECMs in the performance contract. Load flexibility - such as load shifting (through thermal or electrical energy storage), load shedding through advanced controls, and generation through onsite generation - should be evaluated in the ECM package if such ECMs are considered. Ensure that switching from a third-party offsite provider would not carry future standby charges, or that those charges are accounted for in the utility budget.

- If ECMs with load flexibility such as energy storage, onsite generation, and/or new central plants are being considered for use with GEB, the site should ensure there is adequate space for installation.

- The structure of any existing O\&M contract should be considered at this phase, as well as the potential for adding O\&M of additional equipment to it. Including O\&M services in the performance contract is an alternative approach.

- Focus on buildings with standard variable air volume systems, preferably all-electric buildings with zone-level electric reheat at terminal units (fan coil units, variable air volume 
boxes, etc.)

- BAS trend data should be analyzed as a part of the PA to determine AHU fan loading (percent variable frequency drive operating speed).

- Buildings with larger AHUs should be prioritized over buildings with smaller AHUs. For example, if a 200,000 $\mathrm{ft}^{2}$ office has four large AHUs that serve the entire building, it will be less expensive and more profitable to implement GEB control strategies on these AHUs than in a 200,000 $\mathrm{ft}^{2}$ office building with 20 smaller distributed AHUs.

- In general, it is recommended to avoid underfloor air distribution systems as they are normally operated as constant value systems with very few fan variable frequency drive reset options for load shed measures.

- If the proposed GEB measures focus on load shed and the ECMs include plug load controls, targeting buildings with GSA-only tenants is recommended. GSA has the ability to implement plug load control software on GSA computers, but not on non-GSA-owned computers, for example.

\section{GEB-Ready Analysis}

If a particular site is not currently a good fit for certain GEB measures for either technical or economic reasons, GSA could still request that the contractor consider how to implement ECMs that would allow for GEB integration and controls either at a later date or allow for a potential future modification to the performance contract after building loads are better understood or technology matures. For example, a "GEB-ready" approach could include lighting controls that are integrated with the BAS or whole-building EMIS with the capability of implementing demand flexibility at a later date as utility price or OpenADR 2.0 control signals are initiated by the utility. In that case, the contract could be modified in the future to include future controls upgrades or other GEB-related measures as utility incentives, rate structures, and grid signals evolve over time.

\subsubsection{Preliminary Assessment Report Requirements}

The PA report should include a summary of the prioritized buildings and review of targeted energy efficiency, distributed energy resources, and demand flexibility/GEB measures that could apply to each individual building.

The PA should explicitly mention GEB measures that will be further evaluated in the IGA, along with anticipated control sequences and any additional equipment, control platforms, sensors, or meters that are required for implementation. Table 7 is a sample high-level summary table appropriate for use in a PA report. 
Table 7. Preliminary Assessment GEB Summary Table

\begin{tabular}{|c|c|c|c|c|c|c|}
\hline GEB Measure & $\begin{array}{l}\text { GEB } \\
\text { Flexibility } \\
\text { Mode } \\
\text { (Shed, } \\
\text { Shift, } \\
\text { Generation) }\end{array}$ & $\begin{array}{l}\text { GEB } \\
\text { Benefits }\end{array}$ & $\begin{array}{l}\text { Additional } \\
\text { Equipment } \\
\text { Required for } \\
\text { Implementati } \\
\text { on }\end{array}$ & $\begin{array}{l}\text { Proposed } \\
\text { Control } \\
\text { Sequence } \\
\text { (noting time } \\
\text { of day and } \\
\text { seasonal } \\
\text { differences) }\end{array}$ & $\begin{array}{l}\text { Anticipated } \\
\text { M\&V } \\
\text { Approach }\end{array}$ & $\begin{array}{l}\text { Tenant } \\
\text { Impact }\end{array}$ \\
\hline $\begin{array}{l}\text { GEB Measure } \\
\text { \#1 (i.e., lighting } \\
\text { controls) }\end{array}$ & Shed & $\begin{array}{l}\text { E.g., } \\
\text { reduced } \\
\text { peak } \\
\text { demand }\end{array}$ & & & & \\
\hline $\begin{array}{l}\text { GEB Measure } \\
\text { \#2 (i.e., thermal } \\
\text { energy } \\
\text { storage) }\end{array}$ & Shift & $\begin{array}{l}\text { E.g., shift } \\
\text { cooling } \\
\text { load to } \\
\text { off peak } \\
\text { hours }\end{array}$ & & & & \\
\hline
\end{tabular}

The standard ECM summary tables are recommended for use in the PA, with the incorporation of distinct estimated peak demand savings attributable to each GEB measure. Estimates of percent reduction in peak demand and/or percent load that can be shifted can be reported along with general descriptions of the savings opportunity.

\subsubsection{GSA Site-Specific Preliminary Assessment Documentation}

During the PA phase of the project, each individual GSA region, site, or facility is encouraged to provide guidance to the contractor regarding current zone temperature set points, HVAC schedules, light level and control requirements, and any plug loads that may be targeted for GEB ECMs. See Appendix C for more details from the PBS-P100 standards and the required set points.

Once the PA is completed and submitted by the ESCO or utility, GSA should evaluate the GEB measures as a package with the other ECMs in the PA to determine the bundle that is in the agency's and site's best interests for further development.

\subsection{Phase 3: Pre-Award Project Development}

Following agreement on the results of the PA and a GSA decision to move forward, the utility or ESCO will perform an IGA $^{\text {ii }}$ of the facilities to finalize solutions, including ECM details, costs, savings, and financial schedules. To kick off this phase, GSA should confirm the ECMs to be further investigated and developed in the IGA, including efficiency, renewable energy, and GEB strategies.

Operational requirements or limitations that may impact GEB strategies should be provided by

\footnotetext{
ii In a UESC, the IGA may be called a feasibility study. For the purposes of this document, we consider an IGA and a feasibility study to be equivalent.
} 
GSA for any building included in the project. The contractor will adhere to these requirements in performing the IGA and they will be used to develop the final proposal and task order. The IGA will include confirmation or refinement of:

- Baseline energy use and costs

- $\quad$ Specific GEB strategies to develop as ECMs (or as operational strategies for ECMs) in specific facilities

- Savings potential from GEB ECMs found to be cost effective

- O\&M/repair and replacement plan, including schedule and responsibility allocation

- $\mathrm{M} \& \mathrm{~V}$ plan or performance assurance plan for savings and performance verification.

This phase typically begins with an IGA kickoff meeting to ensure all parties are in agreement regarding GEB measures to be further developed in the IGA, agency requirements and expectations, and stakeholder engagement plans. Potential GEB measures will be analyzed in greater detail in the IGA, likely requiring further utility rate analysis and modeling of each measure's potential performance and savings. Regardless of whether the project is being implemented as an ESPC or a UESC, close coordination with the electric utility will be beneficial to quantify the potential of demand response measures and grid-level services.

Any GEB measures to be included in the final proposal should have clearly defined performance estimates, including how the proposed performance was determined, and specific plans for determining and sustaining performance over the term of the contract. Some key GEB evaluation metrics are discussed in the next section.

\subsubsection{GEB Evaluation Metrics}

As GEB measures are being evaluated for a particular site, there are several considerations for modeling and comparing the measures to understand their value potential. Overarching energy efficiency should be captured along with time-dependent impacts of load shed, load shift, and demand response services. It is also important to clearly communicate how metrics support federal and GSA goals, including for energy reduction and clean energy development.

Calculating demand flexibility savings is not entirely straightforward. Modeling tools are still very static in how they model load, and assumptions need to be made to estimate when and how much load can be shed or shifted. Analysis of seasonal hourly load profiles for the whole building and targeted end uses is essential to determine peak demand time windows in which load can be more flexible. Figure 10 shows the total hourly electricity use in terawatt hours in U.S. commercial buildings, broken out by major electric end use for 2018. Each colored bar represents a single end use, and bar labels indicate the total site electricity use that occurs during each hour across the course of the year. ${ }^{28}$ 


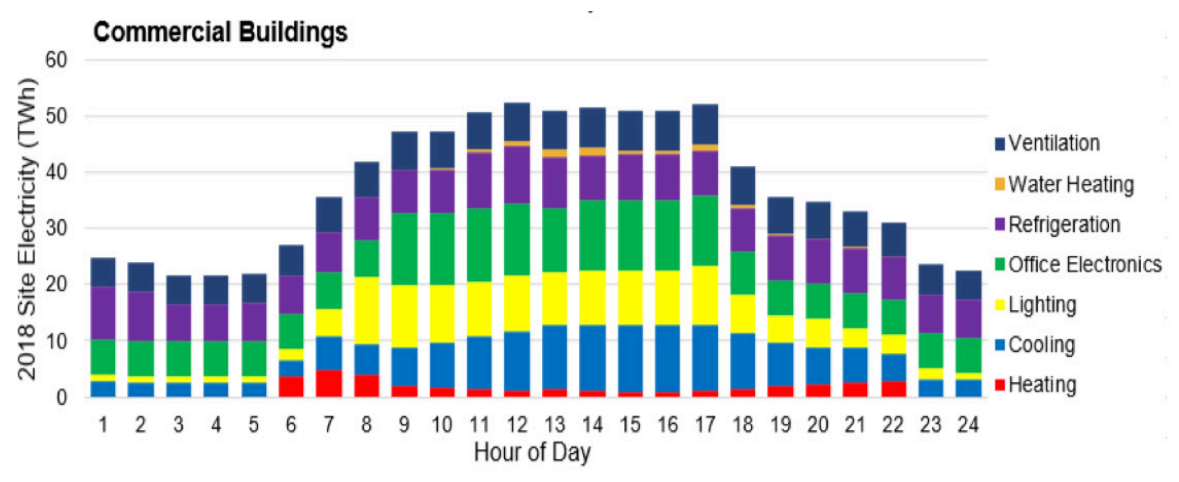

Figure 10. Generic commercial building hourly end-use load profile

Image Credit: U.S. Energy Information Administration 2019 Annual Energy Outlook

It is important that the contractor develop similar aggregate hourly end-use load profile graphs for targeted facilities so that the opportunities for load shed and load shift are well understood, and end use loads with the greatest load shed or load shift potential are targeted for GEB measures.

Without more dynamic modeling tools that can consider TOU utility pricing signals or historical carbon emission data, a time window for each season should be estimated for load shedding. The time window should fall over a few hours of each day, with special consideration for days when peak load is predicted to be the greatest. A percent reduction during that time window can then be estimated based on utility costs and hourly load profiles for each end use, with consideration of weekly and seasonal variations. Similarly, time windows should be defined for end-use systems that offer load shifting. This should include times when shifting can occur and an estimate of the percent load that can be shifted to off-peak times.

A number of metrics can be used to quantify demand flexibility and its annual and seasonal impacts, and should ultimately support federal and GSA goals, including those for energy reduction and clean energy development. One set of metrics is available from the New Buildings Institute's GridOptimal Buildings Initiative, which evaluate the quality of building-grid interactions and building capabilities. ${ }^{29}$ Because many GEB solutions also enable energyefficient operation, metrics should also quantify both energy efficiency and demand flexibility. It may also benefit the project to consider carbon reduction. A non-exhaustive list of higher-level metrics that could be used in the IGA for GEB measures is provided in Table 8. 
Table 8. Investment Grade Audit GEB Metrics Summary

\begin{tabular}{|c|c|}
\hline $\begin{array}{l}\text { Quantitative } \\
\text { Objectives for } \\
\text { Demand } \\
\text { Flexibility }\end{array}$ & Metrics \\
\hline $\begin{array}{l}\text { Energy } \\
\text { efficiency } \\
\text { savings (from } \\
\text { GEB solution) }\end{array}$ & $\begin{array}{l}\text { Energy savings: } \mathrm{kWh} / \mathrm{year} \text { and } \% \text { savings } \\
\text { Energy intensity savings: } \mathrm{kWh} / \mathrm{ft}^{2} / \text { year }\end{array}$ \\
\hline $\begin{array}{l}\text { Continuous } \\
\text { demand } \\
\text { management }\end{array}$ & $\begin{array}{l}\text { Monthly peak demand reduction: } \mathrm{kW} \text { and } \% \\
\text { Summer and winter average peak } \mathrm{kW} \text { reduction }\end{array}$ \\
\hline Peak load shed & $\begin{array}{l}\text { Demonstrated load shed based on a utility signal: } \\
\text { a. Demand shed per event: Average kW reduction (for } \\
\text { shed) over a specified time window } \\
\text { b. Average \% demand reduction } \\
\text { c. Demand shed intensity: W/ft }{ }^{2}\end{array}$ \\
\hline Load shift & $\begin{array}{l}\text { Average demand increase or decrease over shift days } \\
\text { during the summer and winter: } \mathrm{kW}, \mathrm{W} / \mathrm{ft}^{2}, \% \\
\text { Net building consumption change in } 24 \text { hours over shift days } \\
\text { during the summer and winter: } \%\end{array}$ \\
\hline $\begin{array}{l}\text { Carbon } \\
\text { reduction }\end{array}$ & $\mathrm{CO}_{2} / \mathrm{ft}^{2} /$ year \\
\hline $\begin{array}{l}\text { Cost- } \\
\text { effectiveness }\end{array}$ & $\begin{array}{l}\text { Use site specific utility rate } \\
\text { Cost savings due to efficiency: } \$ / y r \\
\text { Cost savings due to load shed/shift: } \$ / y r \\
\text { Simple payback }\end{array}$ \\
\hline
\end{tabular}

Once energy and demand savings are quantified, the contractor will need to analyze the utility rate structure to accurately apply energy and peak demand rates to calculate cost savings. Although demand savings has historically been considered a risk to the agency, incorporating measures to capture demand savings and moving to demand-centric rates can lead to more accurate energy cost savings and set the agency up to better respond to rate changes in the future. Additional non-energy considerations that align with the GEB measures' integration and compatibility with the building management and communication systems should also be captured and communicated. Some potential questions for the contractor include:

- Does the technology accept one- or two-way communication from the grid?

- What communication protocol is used to communicate with the technology and the utility (e.g., OpenADR, IEEE 2030.5, proprietary)?

$\circ$ What cybersecurity implications are associated with the GEB measure? Are the implications acceptable, or can the GEB strategy meet site cybersecurity requirements?

- What intelligence or logic does the GEB measure use to adjust behavior to provide grid response? Responses could include: (1) static: vendor-defined modes including default control sequences; (2) programmable: user-defined responses to grid signals, preprogrammed; or (3) optimized: the system combines grid signals with functional goals to determine operation.

- Are there any impacts from implementing the GEB measure on building services? This could include effects on light level, hot water temperatures, space temperatures, or 
ventilation rates. Responses should indicate the impact level as none, minimal, or significant.

- Does the GEB measure require additional energy to deliver grid services relative to the baseline energy? Note that this can be negative. Responses should indicate the level of the penalty as none, minimal, or significant.

- Is there a pricing structure related to the GEB measure implementation, such as a Software-as-a-Service or subscription fee?

\section{Recommended Content for GEB Measure Summaries}

The following data is recommended for inclusion in each GEB ECM write-up in the IGA. See Appendix A for additional detail on these recommended requirements.

- GEB technology manufacturer

- Intended end use

- Key operating assumptions

- Communication protocols

- Controller response time

- Maintenance requirements

- Potential or proposed tenant impacts

- Penalties for nonperformance.

\subsubsection{IGA M\&V, Performance Assurance, and Risk Allocation}

Guaranteed energy performance and savings is required by ESPC legislation and is verified through $\mathrm{M} \& \mathrm{~V}$ as agreed upon in an $\mathrm{M} \& \mathrm{~V}$ plan developed in the IGA. The measurements and activities described in the plan will be carried out at least annually, and more frequently if required to ensure performance of GEB ECMs. While guarantees are optional in UESCs, a performance assurance plan will be developed during the IGA that includes performance metrics for each ECM, commissioning and demonstration of ECM performance and capability to generate savings, O\&M, and periodic retro-commissioning of ECMs. The M\&V recommendations provided below may be applied to either guaranteed savings verification or performance assurance activities.

When developing the facility energy baseline, it is important to consider whether whole-building and submetered end-use data is available to capture opportunities for demand flexibility at both the end-use (e.g., lighting, plug loads) and/or whole-building level. In addition, the timing for baseline data collection will vary with specific GEB technology and should account for seasonal differences in demand flexibility.

The International Performance Measurement and Verification Protocol (IPMVP) ${ }^{30}$ was created to encourage consistency in energy savings calculation methods. ${ }^{31}$ IPMVP was used to create FEMP's M\&V Guidelines, Measurement and Verification for Performance-Based Contracts Version 4.0, which outlines the principles, methodology, options, and $\mathrm{M} \& \mathrm{~V}$ plan requirements for federal ESPC projects. ${ }^{32}$ The M\&V Guidelines can also be used in developing UESC 
performance assurance plans. The goal of the $M \& V$ or performance assurance plan should be to balance the cost of $M \& V$ with the risk that savings will not be achieved, with more emphasis on the GEB measures that are projected to result in the most energy and cost savings.

While it is technically possible to apply any one of the Guidelines' M\&V options (A, B, C, or D) to GEB measures, Option B (Retrofit Isolation with All Parameter Measurement) and Option C (Whole Facility Measurement) are the two approaches best suited to appropriately capture impacts of demand reduction. If AMI, submeter, and BAS trend data are used in determining the energy baseline, the same data can be used in post-installation and performance period $M \& V$ and a greater percentage of ECMs can use Option B, generally considered a highly reliable and desirable M\&V option.

Option $\mathrm{C}$ uses historical utility billing data and a mathematical model to describe how the building operated in the past. Models are typically formulated using linear regression, where the "dependent variable" (usually metered usage at a given time) is derived based on the value of "independent" variables, such as weather and occupancy conditions. For GEB measures that are applied to end-use loads like lighting, HVAC, and plug loads, Option B is recommended. For whole-building GEB solutions that apply to multiple end use loads, Option C is recommended.

Table 9 outlines recommended M\&V key performance indicators for GEB ECMs, and considerations that are recommended for inclusion in the $\mathrm{M} \& \mathrm{~V}$ and/or performance assurance plan.

Table 9. Investment Grade Audit GEB M\&V Summary

\begin{tabular}{|c|c|c|}
\hline ECM & $\begin{array}{l}\text { Key Performance } \\
\text { Indicators/M\&V Point } \\
\text { Recommendations }\end{array}$ & $\begin{array}{l}\text { M\&V/Performance Assurance } \\
\text { Plan Considerations }\end{array}$ \\
\hline Automated lighting controls & $\begin{array}{l}\text { - Spot measurement of light } \\
\text { level per zone } \\
\text { - Lighting schedule per zone } \\
\text { - Spot measurement of lighting } \\
\text { fixture power at full power } \\
\text { - Spot measurement of light } \\
\text { fixture power during a } \\
\text { demand event } \\
\text { - Continuous measurement of } \\
\text { lighting control system } \\
\text { response time, duration, and } \\
\text { frequency of demand events }\end{array}$ & $\begin{array}{l}\text { Visual comfort: document change } \\
\text { in accepted ranges of interior } \\
\text { illuminance levels }(\%)\end{array}$ \\
\hline
\end{tabular}




\begin{tabular}{|c|c|c|}
\hline ECM & $\begin{array}{l}\text { Key Performance } \\
\text { Indicators/M\&V Point } \\
\text { Recommendations }\end{array}$ & $\begin{array}{l}\text { M\&V/Performance Assurance } \\
\text { Plan Considerations }\end{array}$ \\
\hline Advanced plug load controls & $\begin{array}{l}\text { - Documentation of plug load } \\
\text { equipment schedule } \\
\text { - Spot measurement of plug } \\
\text { load fixture power at full } \\
\text { power } \\
\text { - Spot measurement of plug } \\
\text { load fixture power during a } \\
\text { demand event } \\
\text { - Continuous measurement of } \\
\text { plug load controls, response } \\
\text { time, duration, and frequency } \\
\text { of demand events }\end{array}$ & $\begin{array}{l}\text { Occupant } \\
\text { impact: document process to } \\
\text { ensure no perceived change in } \\
\text { tenant interaction with plug loads }\end{array}$ \\
\hline HVAC controls & $\begin{array}{l}\text { - HVAC key performance } \\
\text { indicators and BAS point } \\
\text { measurements are dependent } \\
\text { GEB ECMs implemented: } \\
\text { - Continuous measurement of } \\
\text { HVAC controls response time, } \\
\text { duration, and frequency of } \\
\text { demand events }\end{array}$ & $\begin{array}{l}\text { Thermal comfort: \% } \\
\text { increase/decrease in hot/cold } \\
\text { calls, and/or \% } \\
\text { increase/decrease within/out of } \\
\text { comfort range (e.g., simplified } \\
\text { ASHRAE model based on } \\
\text { temperature, relative humidity, } \\
\text { winter/summer) } \\
\text { Indoor air quality: change in } \\
\text { accepted ranges of interior } \mathrm{CO}_{2} \\
\text { levels }\end{array}$ \\
\hline $\begin{array}{l}\text { Whole-building EMIS with GEB } \\
\text { control }\end{array}$ & $\begin{array}{l}\text { - Weather-normalized whole- } \\
\text { building } 15 \text {-minute demand } \\
\text { reduction based on outside air } \\
\text { conditions, day of week, etc. } \\
\text { - Additional key performance } \\
\text { indicators and M\&V points } \\
\text { based on subsystems } \\
\text { included }\end{array}$ & $\begin{array}{l}\text { Thermal comfort: \% } \\
\text { increase/decrease in hot/cold } \\
\text { calls, and/or \% } \\
\text { increase/decrease within/out of } \\
\text { comfort range (e.g., simplified } \\
\text { ASHRAE model based on } \\
\text { temperature, relative humidity, } \\
\text { winter/summer). }\end{array}$ \\
\hline PV & $\begin{array}{ll}\text { - } & \text { 15-minute PV system } \\
\text { electricity production }(\mathrm{kWh}) \\
\text { - } 15 \text {-minute PV system standby } \\
\text { energy usage }(\mathrm{kWh}) \\
\text { - } \text { Plane of array incident solar } \\
\text { radiation }\left(\mathrm{kWh} / \mathrm{m}^{2}\right) \\
\text { - } \mathrm{PV} \text { cell temperature } \\
\text { - } \mathrm{PV} \text { system performance ratio }\end{array}$ & $\begin{array}{l}\text { Meter PV production separately, } \\
\text { include web-based monitoring. } \\
\text { PV production forecasting may } \\
\text { allow for more sophisticated } \\
\text { dispatch of a battery when } \\
\text { applicable. }\end{array}$ \\
\hline $\begin{array}{l}\text { Electrical energy storage } \\
\text { (stationary batteries, mobile } \\
\text { batteries, and bidirectionally } \\
\text { charged EV) }\end{array}$ & $\begin{array}{l}\text { - Charging power (kW AC) and } \\
\text { charging time (hrs, hr of day) } \\
\text { - Discharging power (kW AC) } \\
\text { and discharging time (hours, } \\
\text { hour of day) } \\
\text { - State of charge (\% or kWh) } \\
\text { - } \text { Round trip efficiency }(\%) \\
\text { - Maximum depth of discharge } \\
\text { (daily basis, \% or kWh) }\end{array}$ & $\begin{array}{l}\text { Meter battery charge/discharge } \\
\text { separately, track battery } \\
\text { degradation. Measure battery's } \\
\text { performance at reducing peak } \\
\text { load compared to baseline } \\
\text { demand. } \\
\text { Measure battery's performance } \\
\text { at shifting load during times of } \\
\text { low and high energy cost. }\end{array}$ \\
\hline
\end{tabular}




\begin{tabular}{|c|c|c|}
\hline ECM & $\begin{array}{l}\text { Key Performance } \\
\text { Indicators/M\&V Point } \\
\text { Recommendations }\end{array}$ & $\begin{array}{l}\text { M\&V/Performance Assurance } \\
\text { Plan Considerations }\end{array}$ \\
\hline Thermal energy storage & $\begin{array}{l}\text { - Daily and peak ton-hrs of } \\
\text { cooling } \\
\text { - Charging cooling energy (ton- } \\
\text { hrs) and charging time (hrs, hr } \\
\text { of day) } \\
\text { - Discharging cooling energy } \\
\text { (ton-hrs) and charging time } \\
\text { (hrs, hr of day) } \\
\text { - Cooling system electrical } \\
\text { power (kW, kWh, based on hr } \\
\text { of day) } \\
\text { - Supply and return water } \\
\text { temperature ( }{ }^{\circ} \mathrm{F} \text { ) } \\
\text { - Supply and return water flow } \\
\text { rate (gallons per minute) }\end{array}$ & $\begin{array}{l}\text { Thermal comfort: \% } \\
\text { increase/decrease in hot/cold } \\
\text { calls, and/or \% } \\
\text { increase/decrease within/out of } \\
\text { comfort range (e.g., simplified } \\
\text { ASHRAE model based on } \\
\text { temperature, relative humidity, } \\
\text { winter/summer). }\end{array}$ \\
\hline
\end{tabular}

As shown in Figure 11, ECM savings will always have some uncertainty due to impacts of weather, occupancy, equipment use, and other variables. While more rigorous $M \& V$ can reduce the amount of savings uncertainty, there may be some variability in the exact amount of demand curtailed or number of demand response events per year, making certain demand response measures difficult to quantify with confidence during the IGA. This should be addressed among GSA, the ESCO, and the utility when developing the energy baseline and M\&V plan to agree upon a strategy for addressing variable savings from certain GEB measures. For ESPCs, this may affect the level of savings the ESCO is willing to guarantee (i.e., percent of estimated savings). For demand response ECMs in UESCs, performance assurance activities may include monitoring utility data and recommissioning where appropriate. 


\section{GEB Challenge \#3: Potential to Introduce Annual Cost Savings Variability}

For most ECMs in a performance contract, engineering calculations provide annual savings estimates, which are typically escalated at an agreed-upon rate. The reality is that most annual energy cost savings fluctuate, but GEB measures may have a higher degree of annual savings variability.

For example, the realized demand savings could change from month to month depending on the number of demand response events, and demand response utility incentives are typically only guaranteed for the first one to three years of the contract, which must be considered in annual savings and performance guarantees. M\&V for variable savings and demand management may present challenges, and the level of savings guaranteed may be lower with GEB ECMs until confidence in these strategies grows.

As an illustration of this concept, in Figure 11, the blue line shows that contract payments should be less than estimated savings (green line) and that the agreed-upon risk and uncertainty determine the percent difference between the two. The yellow line illustrates that the actual savings fluctuates somewhat from year to year. GEB ECMs may increase the variability of actual savings from year to year, an important consideration when selecting an $M \& V$ approach and determining annual contract payments.

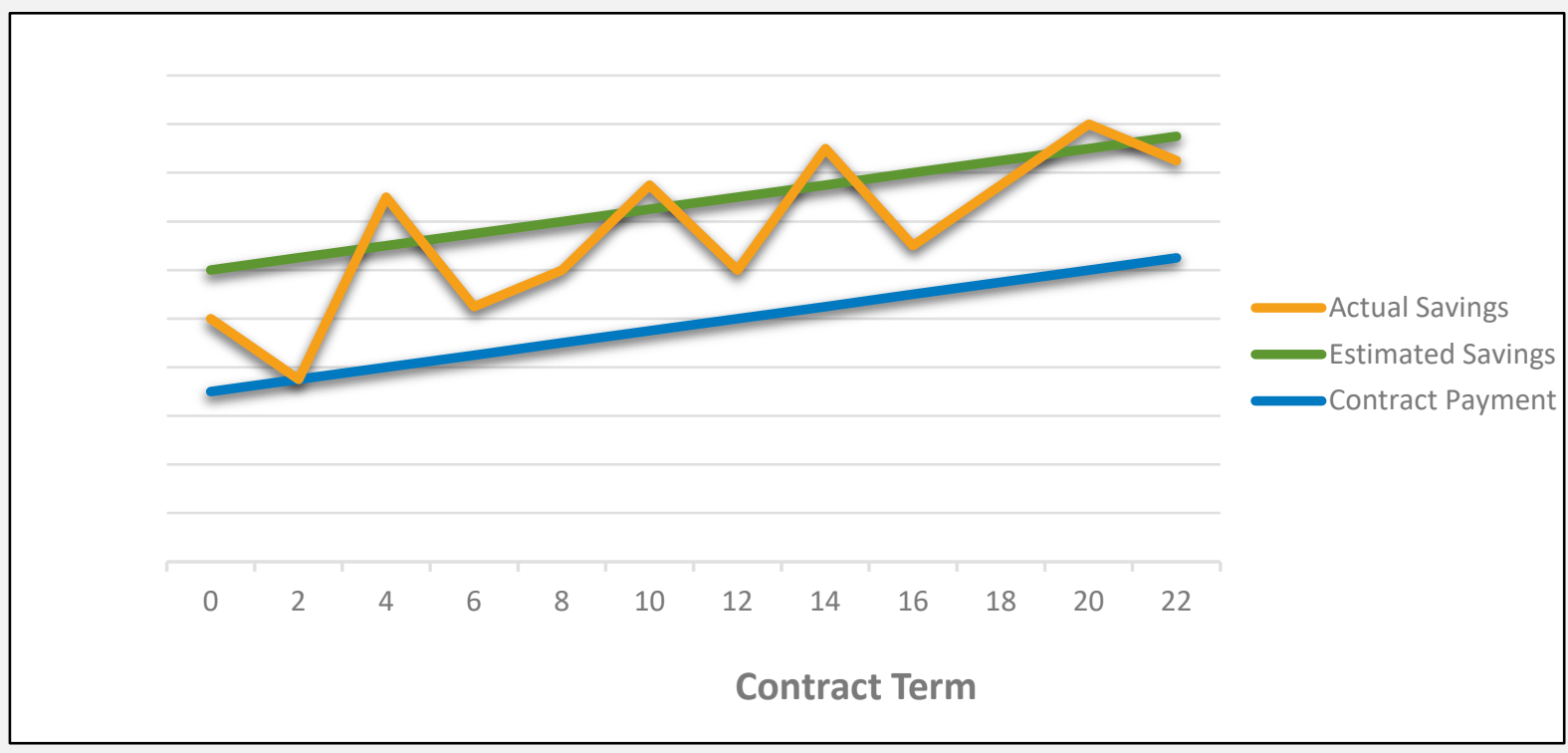

Figure 11. Performance contracts annual energy cost savings variability

\section{Recommendation}

GEB measures that continuously manage and reduce demand — such as energy storage, can help tremendously to reduce the risk of annual cost savings variability. GEB measures associated with traditional utility-sponsored demand response should be included where they can, and the terms of the incentive and specific number of demand response days per year should be pre-negotiated to reduce the potential savings uncertainty. 


\section{Risk, Responsibility, and Performance Matrix}

The DOE ESPC Risk, Responsibility, and Performance Matrix ${ }^{33}$ (RRPM) provides a summary of financial, operational, and performance risks and responsibilities that may affect project costs and savings; structure for decision making and negotiations; and documentation of decisions regarding allocation of risks and responsibilities. The RRPM is a contractual requirement for projects using the DOE ESPC IDIQ and can also be beneficial when used for UESC projects.

There are a few areas of the RRPM that should be addressed specifically for GEB ECMs. These include:

\section{- Financial Risks}

- Energy prices - Energy prices may rise or fall over time and are agreed upon at task order award.

- Neither the contractor (ESCO) nor the customer (ordering agency) has significant control over actual energy prices. This risk applies to any performance contract but is mitigated through agreed-upon escalation rates. An additional consideration for GEB ECMs may result if a measure is tariffdependent (e.g., TOU, variable time pricing, demand reduction incentives).

- M\&V confidence - Guaranteeing and verifying savings that are potentially variable (such as modulating loads) may present challenges.

- Clarify how project savings are being verified (e.g., equipment performance, operational factors, energy use) and the impact on $\mathrm{M} \& \mathrm{~V}$ costs. For certain GEB measures, this may require interaction with the electric utility company.

\section{- Operational Risks}

$\circ$ Load - Equipment and building loads can change over time, and the customer generally has control over hours of operation, conditioned floor area, and intensity of use.

- Clarify whether equipment loads are measured or stipulated and the impact if those loads change over time (details related to GEB load shift or modulation).

- User participation - Tenant acceptance of and interaction with certain measures. If user participation is required, savings can be affected.

- Clarify what degree of user participation is needed and use monitoring training to mitigate risk. Review and document assumptions and consider $\mathrm{M} \& \mathrm{~V}$ to confirm capacity to meet savings (e.g., confirm controls function properly).

\section{- Performance Risks}

- Equipment performance - The contractor has responsibility to demonstrate that the new improvements meet expected performance levels.

- Clarify who is responsible for initial and long-term performance, how it will be verified, and what will be done if performance does not meet expectations. This is particularly important where coordination with the utility is required for GEB ECMs dependent on tariff adjustments, incentives, or real-time demand response, and to ensure PBS-P100 standards are met. 


\section{Contractor ECM Mock-ups}

During the IGA phase of the contract, the ESCO or utility may mock up various lighting, building envelope, and plug load retrofit options so GSA and the tenants can see proposed solutions prior to installation. If any of these ECMs will have GEB-related controls, GSA is encouraged to work with the contractor to include any GEB ECM that will potentially modify space conditions in any way in the mock-up and use this as a means to vet the proposed lighting, building envelope, or plug load controls with both building staff and building operators. This is an important step in stakeholder engagement to ensure tenant impacts are positive and acceptable.

When the IGA has been completed, the results including the M\&V or performance assurance plan, O\&M requirements, and financial schedules will be provided in a final proposal. GSA will have the opportunity to negotiate the final terms and conditions prior to awarding the project, so thorough review and discussion is imperative.

\subsection{Phase 4: Project Implementation}

During ECM implementation, the GEB measures will be installed to specification, tested, and programmed to ensure operability for optimum savings. As GEB is a relatively new concept, the contracting officer should be kept informed of the GEB strategy and monitor its implementation during the construction phase (typically through the

Phase 4 tasks:

- Measure installation

- Commissioning

- Staff and tenant training contracting officer's representative or agency construction project manager). The site and tenants should also be kept informed of installation schedules and any GEB testing to ensure that they are not negatively impacted.

Once ECM installation is complete, commissioning will be performed to verify functionality and operability, demonstrate performance meets design specifications and GSA requirements, and document results within a commissioning report. It is critical that commissioning be complete, documented, and reviewed prior to ECM acceptance. Post-implementation M\&V will also be performed to demonstrate the ECM's capability to generate savings. With GEB measures, particular emphasis should be placed on evaluating performance both in terms of load reduction and tenant impacts. For seasonal GEB measures such as those that affect heating or cooling systems, waiting until the following winter or summer to evaluate seasonal impacts should be considered. Conditional acceptance could be issued for these GEB measures that may be seasonal in their use.

GSA staff (and potentially tenants) will be trained as needed in the operation, maintenance, recommissioning, and monitoring of GEB measures to be performed throughout the performance period term. The potential for tenants to impact projected savings through manual override of controls should generally be avoided; however, training for tenants on acceptable modifications to the anticipated GEB measures should be included in this process, if applicable. Training plans 
should include hands-on learning, anticipate the potential for staff turnover, clearly document GEB practices and include succession planning if necessary.

Commissioning and post-installation performance measurements must occur prior to ECM acceptance, and for GEB measures this may mean a period (e.g., 30 days) of ensuring that controls allow demand reduction and response to occur as needed to ensure savings or achievement of incentives. In the case of demand response programs, coordination with a site's utility may be required to ensure that GEB measures respond to utility signals.

\subsection{Phase 5: Post-Acceptance Performance Period}

For GEB projects to be successful, all ECMs must be properly operated, maintained, recommissioned, repaired, or replaced to sustain performance and savings. Performance assurance and/or $M \& V$ activities will be carried out by the utility, ESCO, and GSA as assigned in the task order to ensure the GEB measures deliver the agreed-upon performance and energy cost savings. Figure 12 summarizes the annual $\mathrm{M} \& \mathrm{~V}$ or performance

Phase 5 tasks:

- Performance assurance

- M\&V

- Reporting assurance activities that will be performed, including agency and contractor responsibilities.

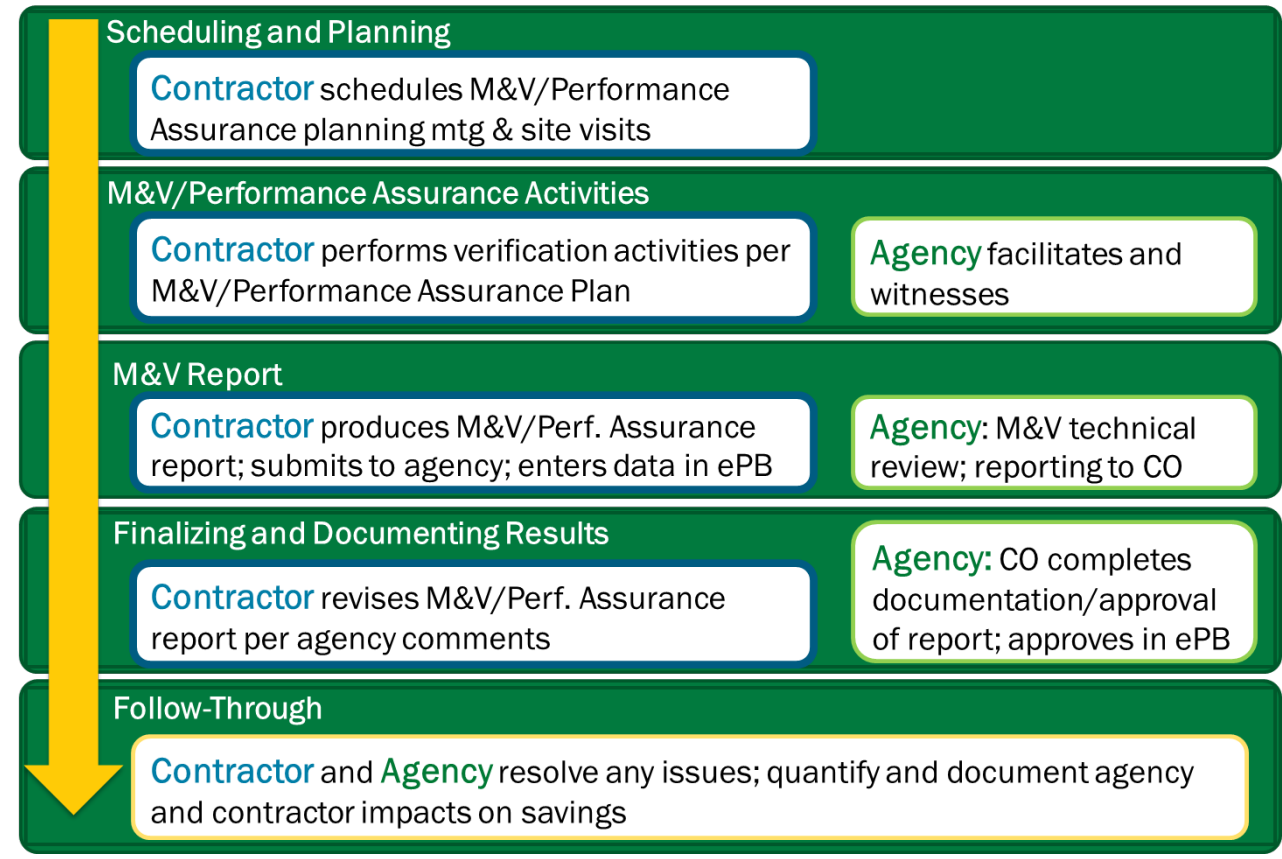

Figure 12. Annual M\&V activity responsibilities

$\mathrm{M} \& \mathrm{~V}$ or performance assurance activities should follow the plan developed in Phase 3 and described in Section 5.4.2. This process includes coverage of GEB measures as well, with several additional considerations. Certain GEB measures, such as building loads programmed to respond to demand response events, may require monthly or more frequent monitoring to ensure that the site remains eligible for the program. If there is 
variation between the estimated and guaranteed savings, GSA should document that there were no potential tenant causes for this difference.

Coordination with the electric utility should ensure any incentives or credits for demand response or curtailment measures are accounted for. All $\mathrm{M} \& \mathrm{~V}$ or performance assurance measurements and calculations should be documented in an annual $M \& V$ or performance assurance report, including any $\mathrm{O} \& \mathrm{M}$, recommissioning, impacts of agency operations or maintenance, and potential shortfalls and corrective actions. As ESPC and UESC project terms can last up to 25 years, proper measurement and monitoring of GEB measures, along with documentation of performance or issues, should occur for the entire term, or for the time that the GEB measure remains in place (e.g., for demand response programs that incentivize performance for a limited time, savings will only accrue and payments will only be made for that time period). GSA and the contractor should revisit any incentive-based programs with the electric utility throughout the performance period as there may be opportunities to take advantage of new programs and maximize long-term savings.

\section{Conclusions}

GEB offers an integrated approach to coordinating buildings' electrical and thermal loads for cost savings, continuous demand management, and optimized energy use for additional grid services. With this blueprint, GSA can expand its innovative use of performance contracts for deep energy retrofits in a new direction, incorporating GEB into its portfolio of commercial office spaces. Due to the sheer number of sites under GSA management, GSA could first pursue a screening methodology to filter down to the sites with the highest economic potential for GEB integration. These sites commonly have high demand and/or energy charges, TOU rates, or utility or state incentives that promote flexible building energy consumption. With promising GEB candidate sites identified, GSA could initiate performance contract development under ESPC or UESC authorities and follow step-by-step guidance informed by prior GEB project lessons learned. This includes considerations for NOO language, PA evaluation methodologies for major GEB functionalities (e.g., load shed, shift, modulation), and GEB technologies for consideration. IGA-stage GEB evaluation metrics and $M \& V$ requirements help ensure their successful implementation and long-term performance.

Key takeaways from this report include the importance of strategic selection of sites with utility rates and incentives favorable to GEB; early identification of GEB as a priority in the NOO stage of the contracting process; better integration of GEB within major building renovations; and careful consideration of GEB M\&V. 


\section{Appendix A. Utility Rate Structure and Grid Services Analysis}

Typically, at the PA stage of the project, the site's blended electricity rates (total utility cost divided by total electric consumption) are used to estimate annual energy cost savings and the simple payback period. The utility or ESCO provides financial schedules that include high-level cost and savings estimates for each ECM and for the project as a whole, including estimated costs for annual O\&M, repair and replacement, and $M \& V$ or other performance assurance services.

For performance contracts that include plans to integrate GEB measures, the following is a list of recommendations for utility rate structure, ECM economic calculations, incentives, and grid services analysis that should be considered during the PA.

- Since GEB measures are demand-centric, GSA could require that actual (rather than blended) electric rates be used for calculating energy cost savings and project economics. For example, PV system economics will look much more favorable using blended rates rather than using actual energy and demand rates, as PV normally only offsets a portion of the monthly demand charges due to the variability of PV production. Proposed economics of PV systems can impact other load-shifting technologies such as battery storage, and the more accurate these initial estimates are, the more likely they will be properly screened during the PA phase and not dropped during the IGA.

- Identifying the demand cost portion of a site's utility bill could be another useful measure for evaluating the favorability of GEB for a site. Figure A-1 shows this proportion of demand charges as a portion of GSA sites' overall utility costs, as well as the size of opportunity, below.
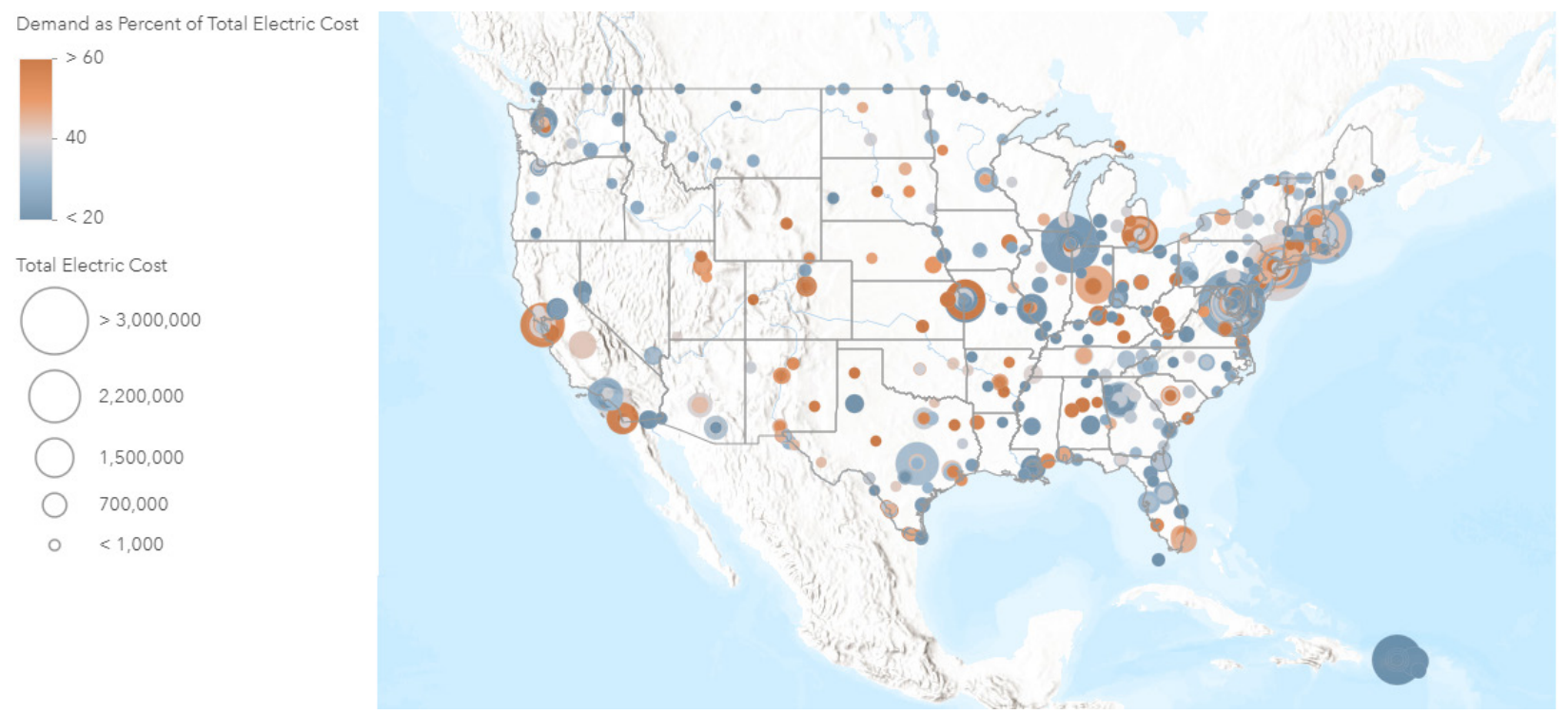

Figure A-1. Electric costs and estimated demand charges at GSA sites (GSA GIS Platform) 
- GSA could require an in-depth utility rate structure analysis in the PA to analyze different rate structures and identify the best rate structure for both the site and project. This rate could then be used in the energy cost savings calculations for both the PA and IGA. For example, some utilities offer alternative TOU rates that may allow a GEB project to obtain greater savings than under the site's existing tariff.

- Individual measures do not have to be cost effective on their own, but the ESPC project as a whole must be life cycle cost effective, and measures with very long paybacks may be a burden on the project. If there are specific measures that are important to the facility or integral to the function of a GEB measure, but are not quite cost effective, GSA may consider providing agency funds to include these in the project. Availability of funds could be explored at this time, with specific decisions made in the IGA phase.

- GSA (and the ESCO if using an ESPC) could meet with the utility in the PA phase to understand what grid services are most important to the utility, particularly if any of those services are incentivized by the utility. There may be potential demand response or ancillary services programs that could be tapped by means of the GEB measures. 


\section{Appendix B. GEB ECM Write Up Considerations}

For each GEB ECM, consider describing GEB technology functionality and attributes, ${ }^{\text {iii }}$ including:

i) Targeted end uses that the solution addresses

ii) Flexibility modes supported

(1) Efficiency, shift, shed, modulate, generate

iii) One- or two-way communication with utility

iv) Communication protocol used by the utility to communicate with the solution or technology

(1) OpenADR, IEEE 2030.5 (Smart Energy Profile 2.0), Proprietary

v) Behavior on connectivity loss

(1) Grid interactive functionality of the component when communication is not available

vi) Grid-interactive control

(1) The intelligence of logic that the technology implements to adjust its behavior to provide grid response. Control types can include static, programmable, and optimized

vii) Response time

(1) Total elapsed time from the grid sending a signal to a device changing its power level

viii) Duration of response

(1) How long a change in electricity consumption can typically be maintained without unduly compromising building services

ix) Lifetime and maintenance issues

(1) The known extent to which providing grid services could impact equipment life

$\mathrm{x}$ Impact on building services and occupant comfort

xi) Energy penalty

(1) Additional energy required to deliver grid services relative to the baseline energy

xii) Energy storage capability

(1) Ability of a component or system to store energy for load shed or shift events

xiii) Data availability

xiv) Building resilience

xv) Data points integrated

xvi) IT cybersecurity

xvii) Additional technology capabilities or characteristics not covered above.

\footnotetext{
iii Characteristic metrics defined by J. Granderson's (LBNL): Framework and Metrics to Characterize Building Technologies that Can Provide Grid Services (Draft).
} 


\section{Appendix C. Preliminary Assessment Documentation}

The GSA PBS-P100 Facilities Standards for the Public Buildings Service establishes design standards and design criteria for new buildings, repairs and alterations, and facility modernization projects. Any proposed GEB ECM or GEB control strategy needs to comply with PBS-P100, particularly in relation to HVAC set points, interior comfort, and interior lighting levels. $^{34}$

\section{HVAC Set Points}

Section 5.2 of the PBS-P100, Mechanical Performance Attributes, outlines requirements for interior temperature, humidity control, air movement, pressure, ventilation, and filtration. The PBS requirements generally follow ASHRAE Standard 55 for interior temperature and humidity and ASHRAE Standard 62.1 for air movement, ventilation rates, and pressurization. ${ }^{35,36}$

For interior temperature, the PBS-P100 requires "control of dry bulb temperature range, allowing for seasonal and unoccupied setpoint adjustment." In the PBS-P100, there are three "Tiers of High Performance" attributes that encourage smaller control zones, better control of building envelope surface temperatures, adaption to individual occupant preferences with the goal of a lower predicted percentage of dissatisfied occupants, and the ability for individualized control of space conditions through the BAS or at the occupant level.

Section 3.7.4 of PBS-P100, Health and Comfort: Environmental Controls further outlines high performance attributes that give employees the ability to control and adjust air ventilation and temperature in enclosed conference rooms and work area zones, and the choice to work in alternative spaces with predesignated environmental conditions such as warmer areas, cooler areas, brighter rooms, etc.

During the PA phase of the project, each individual GSA region, site, or facility is encouraged to provide guidance to the contractor regarding current zone temperature set points, HVAC schedules, and potential allowances. For example, the following inputs should be provided:

- Occupied Space Temperature Set Point - Occupied set points for both heating and cooling mode. For example, occupied heating set point $70^{\circ} \mathrm{F}$ and occupied cooling set point $74^{\circ} \mathrm{F}$.

- Unoccupied Space Temperature Set Point - Unoccupied set points for both heating and cooling mode. For example, unoccupied heating set point $60^{\circ} \mathrm{F}$ and unoccupied cooling set point $85^{\circ} \mathrm{F}$.

- Weekday, Weekend, and Holiday Occupancy Schedule - Occupancy schedule for the facility. For example, all zone temperatures need to be at the occupied set point from 7 a.m. to 5 p.m. Monday through Friday; unoccupied set points applied all other times.

- List of Critical and Noncritical HVAC Zones - A list of critical and noncritical HVAC zones in the buildings.

- Set Point Allowance - Offer guidance to the contractor in relation to any GEB measure that might impact interior thermal comfort, addressing the following questions: 
- Whether the critical zone set points can float up or down during periods, and if so, what the allowable range is, either on a daily basis or during demand events

- Whether the non-critical zone set points float up or down during periods, and if so, what onsite GSA staff designates as the allowable range, either on a daily basis or during demand events.

\section{Lighting Levels}

Section 6.2.2 of PBS-P100, Lighting Quantity recommends following illuminance values recommended by the Illuminating Engineering Society $10^{\text {th }}$ Edition Handbook for horizontal illuminance based on space type and meets the minimum average base surface reflectance recommendations for ceilings, walls and floors. ${ }^{37}$ Tier 1-3 for High Performance has further guidance regarding surface reluctances used in the calculations, as well as percentages of lighting allocated to ambient and task lighting.

Section 3.7.4.2, Lighting/Daylighting further outlines high-performance attributes regarding using lighting fixtures that can provide both downlight (direct) and up-light (indirect) for primary work spaces, ensures all employees are able to control and adjust individual task lighting at their primary work space, and provides guidance regarding use of adjustable window treatments, including blinds and shades, that give the user the ability to control daylight and glare or are automated based on lighting sensors.

During the PA phase of the project, each individual GSA region, site, or facility is encouraged to provide guidance to the contractor regarding light level requirements, overhead versus task lighting requirements, and lighting and window treatment control guidelines. For example:

- Light level requirements - GSA staff are encouraged to provide light level requirements per space type, including the recommended split of overhead versus task lighting percentages.

- List of critical and noncritical lighting zones - GSA staff are encouraged to provide a list of critical and noncritical lighting zones in the buildings.

- Light level and lighting control guidance - GSA is encouraged to provide guidance to the contractor in relation to any GEB measure that might impact interior light levels and proposed lighting control strategies. Guidance should include:

$\circ$ Whether the light levels can be modified for either critical or noncritical zones during peak demand events or on a TOU schedule, and if so, what the allowable range is, either on a daily basis or during demand events

- GSA's recommended demand response control strategy_zone switching, luminaire or lamp switching, or continuous dimming - as well as in what lighting zones these can strategies be deployed.

\section{Plug Loads}

During the PA phase of the project, each individual GSA region, site, or facility is encouraged to provide guidance to the contractor regarding plug loads that can potentially be targeted for GEB ECMs. 
- Controllable Plug Loads - GSA staff are encouraged to indicate which plug loads within the building are options for more advanced automated control.

- Laptops and Personal Computers - GSA staff are encouraged to identify if personal computers and laptops are eligible for more advanced control and if so, what tenant engagement and cybersecurity requirements need to be followed. 


\title{
References
}

\author{
${ }^{1}$ Monica Neukomm, Valerie Nubbe, and Robert Fares. 2019. Grid-interactive Efficient Buildings: Overview. Washington, DC: \\ U.S. Department of Energy. https://www.energy.gov/sites/prod/files/2019/04/f61/bto-geb_overview-4.15.19.pdf. \\ ${ }^{2}$ S. Kiliccote, D. Olsen, M. D. Sohn, and M. A. Piette. 2016. "Characterization of Demand Response in Commercial, Industrial, \\ and Residential Sectors in the U.S.," WIREs Energy Environ. 5: 288-304.
}

${ }^{3}$ M. A. Piette, D. S. Watson, N. Motegi, and S. Kiliccote, “Automated Critical Peak Pricing Field Tests: 2006 Pilot Program Description and Results.” Berkeley, CA: Lawrence Berkeley Natl. Lab., vol. LBNL-59351, 2007.

${ }^{4}$ F. N., S. Katipamula, W. Wang, Y. Xie, M. Zhao, and C. D. Corbin. 2017. "Impacts of Commercial Building Controls on Energy Savings and Peak Load Reduction.” Pacific Northwest Natl. Lab., vol. 25985.

${ }^{5}$ Monica Neukomm, Valerie Nubbe, and Robert Fares. 2019. Grid-interactive Efficient Buildings: Overview. Washington, DC: U.S. Department of Energy. https://www.energy.gov/sites/prod/files/2019/04/f61/bto-geb overview-4.15.19.pdf.

${ }^{6}$ GSA, “Green Building Advisory Committee.” Accessed March 3, 2021. https://www.gsa.gov/governmentwideinitiatives/federal-highperformance-buildings/policy/green-building-advisory-committee.

${ }^{7}$ GSA. 2018. Green Building Advisory Committee Advice Letter on Building \& Grid Integration. https://www.gsa.gov/cdnstatic/Bldg\%20Grid\%20Integration\%20Advice\%20Letter\%202-21-19\%20-\%20508.pdf.

${ }^{8}$ GSA. 2019. Green Building Advisory Committee Federal Building \& Grid Integration: Proposed Roadmap Advice Letter. https://www.gsa.gov/cdnstatic/Bldg\%20Grid\%20Integration $\% 20$ Advice $\% 20$ Letter $\% 20 \mathrm{Phase} \% 20 \mathrm{II} \% 2012-9-19$.pdf

${ }^{9}$ RMI. 2019. Value Potential for Grid-Interactive Efficient Buildings in the GSA Portfolio: A Cost-Benefit Analysis. https://rmi.org/insight/value-potential-for-grid-interactive-efficient-buildings-in-the-gsa-portfolio-a-cost-benefit-analysis/.

${ }^{10}$ GSA. 2020. "Request for Information.” Accessed March 3, 2021. https://www.gsa.gov/governmentwideinitiatives/sustainability/emerging-building-technologies/request-for-information.

${ }^{11}$ More information on these planned technology assessments is available at https://www.gsa.gov/governmentwideinitiatives/sustainability/emerging-building-technologies/ongoing-assessments.

${ }^{12}$ GSA and RMI. 2015. "Energy Efficiency and Net-Zero Buildings: GSA \& RMI Answer the Call.” https://rmi.org/wpcontent/uploads/2017/04/GSA_P to_P WS 2015-Exec_Summ.pdf.

${ }^{13}$ U.S. Department of Energy. 2019. Grid-interactive Efficient Buildings: Overview of Research Challenges and Gaps. Washington, DC: U.S. Department of Energy. https://www1.eere.energy.gov/buildings/pdfs/75470.pdf.

14 U.S. Department of Energy. 2019. Grid-interactive Efficient Buildings: Overview of Research Challenges and Gaps. Washington, DC: U.S. Department of Energy. https://www1.eere.energy.gov/buildings/pdfs/75470.pdf.

${ }^{15}$ California Energy Storage Alliance. 2019. “California Public Utilities Commission.” Accessed March 3, 2021. https://www.storagealliance.org/cpuc.

${ }^{16}$ J. Zhang, J. Jorgenson, T. Markel and K. Walkowicz, "Value to the Grid From Managed Charging Based on California's High Renewables Study," in IEEE Transactions on Power Systems, vol. 34, no. 2, pp. 831-840, March 2019, doi: 10.1109/TPWRS.2018.2872905.

${ }^{17}$ ASHRAE. 2020. "Smart Grid Application Guide.” https://www.ashrae.org/about/news/2020/ashrae-releases-smart-gridapplication-guide-integrating-facilities-with-the-electric-grid.

${ }^{18}$ GSA. 2021. “GSA Properties.” Accessed March 3, 2021. https://www.gsa.gov/real-estate/gsa-properties. 
${ }^{19}$ GSA. 2021. “GSA Regions.” Accessed March 3, 2021. https://www.gsa.gov/about-us/gsa-regions.

${ }^{20}$ Alicen Kandt, Emma Elgqvist, Doug Gagne, Mike Hillesheim, Andy Walker, Jeff King, Jeremy Boak, Jeremy Washington, Cory Sharp. 2017. Large-Scale Power Production Potential on U.S. Department of Energy Lands. NREL/TP-7A40-70526. https://www.nrel.gov/docs/fy18osti/70526.pdf.

${ }^{21}$ Cutler, Dylan, Dan Olis, Emma Elgqvist, Xiangkun Li, Nick Laws, Nick DiOrio, Andy Walker, and Kate Anderson. 2017. "REopt: A Platform for Energy System Integration and Optimization." Renewable Energy 75.

${ }^{22}$ NREL. 2017. "Identifying Potential Markets for Behind-the-Meter Battery Energy Storage: A Survey of U.S. Demand Charges.” Golden, CO: NREL. https://www.nrel.gov/docs/fy17osti/68963.pdf.

${ }^{23}$ An example is the CitySmart program offered by CenterPoint Energy. https://eeprograms.net/centerpoint/citysmart/.

${ }^{24}$ FEMP has developed profiles of demand response and time-variable pricing programs throughout the United States at https://www.energy.gov/eere/femp/demand-response-and-time-variable-pricing-programs.

25 Thomas et. al. 2020. "ASHRAE Smart Grid Application Guide: Integrating Facilities with the Electric Grid." https://www.ashrae.org/about/news/2020/ashrae-releases-smart-grid-application-guide-integrating-facilities-with-the-electricgrid.

${ }^{26}$ Matt Jungclaus, Cara Carmichael, Chris McClurg, Margaret Simmons, Randall Smidt and Kinga Porst Hydras. 2017. "Deep energy retrofits in federal buildings: the value, funding models, and best practices." ASHRAE Transactions 123:1, 55. https://rmi.org/wp-content/uploads/2017/06/ASHRAE-D-LV-17-006.pdf.

${ }^{27}$ Federal Energy Management Program. “Cybersecurity Considerations for Performance Contracts.” Accessed March 3, 2021. https://www.energy.gov/eere/femp/cybersecurity-considerations-performance-contracts.

${ }^{28}$ U.S. Department of Energy. "Grid-interactive Efficient Buildings Technical Report Series: Windows and Opaque Envelope." Washington, DC: U.S. Department of Energy. https://www1.eere.energy.gov/buildings/pdfs/75387.pdf.

${ }^{29}$ Alexi Miller. 2020. “Gridoptimal metrics offer guidance on optimizing building-grid interaction.” New Buildings Institute: May 18, 2020. https://newbuildings.org/gridoptimal-metrics-offer-guidance-on-optimizing-building-grid-interaction/

${ }^{30}$ Efficiency Valuation Organization. 2016. "IPMVP Core Concepts.” Accessed March 3, 2021. https://evo-world.org/en/recentnews-home/1025-a-fresh-look-2016-ipmvp-core.

${ }^{31}$ Efficiency Valuation Organization. “International Performance Measurement and Verification Protocol (IPMVP).” https://evoworld.org/en/products-services-mainmenu-en/protocols/ipmvp.

${ }^{32}$ U.S. Department of Energy. 2015. Measurement and Verification for Performance-Based Contracts, Version 4.0. Washington, DC: U.S Department of Energy. https://www.energy.gov/sites/prod/files/2016/01/f28/mv_guide_4_0.pdf

${ }^{33}$ Energy Savings Performance Contract Risk, Responsibility, and Performance Matrix. Available at https://www.energy.gov/sites/prod/files/2017/12/f46/2017doe idiq rrpm.docx.

${ }^{34}$ GSA. 2017. PBS-P100 Facilities Standards for the Public Buildings Service. https://www.gsa.gov/cdnstatic/2017_Facilities_Standards_\%28P100\%29\%C2\%A0.pdf.

${ }^{35}$ ASHRAE Standard 55, available at https://www.ashrae.org/technical-resources/bookstore/standard-55-thermal-environmentalconditions-for-human-occupancy.

${ }^{36}$ ASHRAE Standard 62.1, available at https://www.ashrae.org/technical-resources/bookstore/standards-62-1-62-2.

${ }^{37}$ Illuminating Engineering Society $10^{\text {th }}$ Edition Handbook. https:/www.ies.org/product/the-lighting-handbook-10th-edition/. 